\title{
Effect of sex on glucose handling by adipocytes isolated from rat subcutaneous, mesenteric and perigonadal adipose tissue
}

\author{
Floriana Rotondo ${ }^{1}$, Ana Cecilia Ho-Palma ${ }^{1}$, Xavier Remesar ${ }^{1,2,3}$, José Antonio Fernández-López ${ }^{1,2,3}$, María del \\ Mar Romero ${ }^{1,2,3}$, Marià Alemany ${ }^{\text {Corresp. 1, 2,3 }}$ \\ ${ }^{1}$ Department of Biochemistry and Molecular Biomedicine, University of Barcelona, Faculty of Biology, Barcelona, Spain \\ 2 Institute of Biomedicine, University of Barcelona, Barcelona, Spain \\ 3 CIBER OBN, Centro de Investigación Biomédica en Red: Obesidad y Nutrición, Barcelona, Spain \\ Corresponding Author: Marià Alemany \\ Email address: malemany@ub.edu \\ Background. Adult rat epididymal adipocytes are able to convert large amounts of glucose to lactate \\ and glycerol. However, fatty acid efflux is much lower than that expected from glycerol levels if they \\ were the product of lipolysis. Use of glucose for lipogenesis is limited, in contrast with the active \\ glycolysis-derived lactate (and other 3-carbon substrates). In this study, we analyzed whether white \\ adipose tissue (WAT) site and sex affect these processes.
}

Methods. Mature adipocytes from perigonadal, mesenteric and subcutaneous WAT of female and male rats were isolated, and incubated with 7 or $14 \mathrm{mM}$ glucose during 1 or 2 days. Glucose consumption, metabolite efflux and gene expression of glycolytic and lipogenesis-related genes were measured.

Results. The effects of medium initial glucose concentration were minimal on most parameters studied. Sex-induced differences that were more extensive; however, the most marked, distinct, effects between WAT sites, were dependent on the time of incubation. In general, the production of lactate was maintained during the incubation, but glycerol release rates increased with time, shifting from a largely glycolytic origin to its triacylglycerol (TAG) lipolytic release. Glycerol incorporation was concurrent with increased TAG turnover: lipolytic glycerol was selectively secreted, while most fatty acids were recycled again into TAG. Fatty acid efflux increased with incubation, but was, nevertheless, minimal compared with that of glycerol. Production of lactate and glycerol from glucose were maximal in mesenteric WAT.

Discussion. Female rats showed a higher adipocyte metabolic activity than males. In mesenteric WAT, gene expression (and substrate efflux) data suggested that adipocyte oxidation of pyruvate to acetyl-CoA was higher in females than in males, with enhanced return of oxaloacetate to the cytoplasm for its final conversion to lactate. WAT site differences showed marked tissue specialization-related differences. Use of glucose for lipogenesis was seriously hampered over time, when TAG turnover-related lipolysis was activated. We postulate that these mechanisms may help decrease glycaemia and fat storage, producing, instead, a higher availability of less-regulated 3-carbon substrates, used for energy elsewhere. 
5 Effect of sex on glucose handling by adipocytes isolated from rat

6 subcutaneous, mesenteric and perigonadal adipose tissue

7

8 Floriana Rotondo ${ }^{1,2}$, Ana Cecilia Ho-Palma ${ }^{1}$, Xavier Remesar ${ }^{1,2,3}$, José Antonio Fernández-

9 López ${ }^{1,2,3}$, María del Mar Romero ${ }^{1,2,3}$ and Marià Alemany ${ }^{1,2,3}$

10

$11{ }^{1}$ Department of Biochemistry and Molecular Biomedicine, Faculty of Biology University of

12 Barcelona, Barcelona, Spain

$13{ }^{2}$ Institute of Biomedicine, University of Barcelona, Barcelona, Spain

$14{ }^{3}$ CIBER-OBN Research Web, Barcelona, Spain

Author for correspondence

Dr. Marià Alemany; Department of Biochemistry and Molecular Biomedicine, Faculty of 
24 Abstract

25 Background. Adult rat epididymal adipocytes are able to convert large amounts of glucose to lactate and glycerol. However, fatty acid efflux is much lower than that expected from glycerol levels if they were the product of lipolysis. Use of glucose for lipogenesis is limited, in contrast with the active glycolysis-derived lactate (and other 3-carbon substrates). In this study, we analyzed whether white adipose tissue (WAT) site and sex affect these processes.

Methods. Mature adipocytes from perigonadal, mesenteric and subcutaneous WAT of female and male rats were isolated, and incubated with 7 or $14 \mathrm{mM}$ glucose during 1 or 2 days. Glucose consumption, metabolite efflux and gene expression of glycolytic and lipogenesis-related genes were measured.

Results. The effects of medium initial glucose concentration were minimal on most parameters studied. Sex-induced differences that were more extensive; however, the most marked, distinct, effects between WAT sites, were dependent on the time of incubation. In general, the production of lactate was maintained during the incubation, but glycerol release rates increased with time, shifting from a largely glycolytic origin to its triacylglycerol (TAG) lipolytic release. Glycerol incorporation was concurrent with increased TAG turnover: lipolytic glycerol was selectively secreted, while most fatty acids were recycled again into TAG. Fatty acid efflux increased with incubation, but was, nevertheless, minimal compared with that of glycerol. Production of lactate and glycerol from glucose were maximal in mesenteric WAT.

Discussion. Female rats showed a higher adipocyte metabolic activity than males. In mesenteric WAT, gene expression (and substrate efflux) data suggested that adipocyte oxidation of pyruvate to acetyl-CoA was higher in females than in males, with enhanced return of oxaloacetate to the cytoplasm for its final conversion to lactate. WAT site differences showed marked tissue specialization-related differences. Use of glucose for lipogenesis was seriously hampered over time, when TAG turnover-related lipolysis was activated. We postulate that these mechanisms may help decrease glycaemia and fat storage, producing, instead, a higher availability of lessregulated 3-carbon substrates, used for energy elsewhere. 
Adipose tissue is a large disperse organ, closely related to most organs, and distributed in anatomically differentiated masses, traditionally considered storage depots of fat reserves. There are marked differences between these sites (Jamdar 1978; Prunet-Marcassus et al. 2006), up to the point that their main common characteristic is the massive accumulation of fat (essentially triacylglycerols, TAG), stored in vacuoles, taking most of the cell space (Rotondo et al. 2016). The marked oxidative metabolism of brown adipose tissue, with multiple (and smaller) fat vacuoles and a large number of mitochondria, contrasts with the predominantly glycolytic activity of the huge single-vacuole adipocytes of white adipose tissue (WAT) (Ho-Palma et al. 2016). Between these extremes, we find a number of intermediate adipocyte phenotypes, such as beige (Wu et al. 2012) or pre-adipocytes (Torio-Padron et al. 2010). The array of cell types, which retain a number of similar characteristics, result in an ample variability of functions of BAT, WAT; but also beige and brite or brown-in-white adipose tissue (Giralt \& Villarroya 2013). Nevertheless, for most of the earlier research, the prevailing idea of WAT function was just that of a fat (energy) storage organ. The dangers derived from WAT (and/or individual adipocytes) hypertrophic growth are closely related to the development of metabolic syndrome (Kaplan 1989), a chronic state of inflammation (Cancello \& Clément 2006). In the last twenty years, many other functions of WAT have been discovered, including the synthesis of hormones and growth factors, which interaction with other organs and cell types potentially affecting overall health. WAT regulatory effects are often exerted by small masses of adipose tissue, such as perivascular (Guzik et al. 2007), pericardial (Greif et al. 2013) or intramuscular (Smith et al. 1998).

The active presence of a large number of other cell types interspersed between adipocytes, such as stem (Zuk et al. 2002), immune system (Qiu et al. 2016), stromal vascular (Ribeiro Silva et al. 2017) and even hematopoietic (Luche et al. 2015) is seldom taken into account from the point of view of substrate handling. Nevertheless, their role is critical for regulation and for other WAT functions. The diversity of cell proportions, functions and site distribution contribute to extend, diversify and specialize the roles of WAT in a number of roles, from the control of energy partition to defense and the control of the function of other organs (Scherer 2006; Alemany 2011). This is largely achieved through hormonal (Kershaw \& Flier 2004) and cytokine (Wisse 2004) signaling. 
84

85

86

87

88

89

90

91

92

93

94

95

96

97

98

99

100

101

102

103

104

105

106

107

108

109

110

111

112

113

114

In mammals, body fat distribution is sex-related, and is more marked in humans (Kuk et al. 2005) than in rodents. Essentially, the differences in WAT distribution are a consequence of differences in overall metabolic function (Ailhaud et al. 1991; Fried et al. 2015); i.e. we have observed, recently, a marked effect of sex on rat WAT amino acid metabolism (Arriarán et al. 2015a; Arriarán et al. 2015b). We also found that WAT, and isolated adipocytes, are able to convert large amounts of glucose into lactate and glycerol (Arriarán et al. 2015c; Ho-Palma et al. 2016), despite its small percentage of active cytoplasm with respect to tissue weight (Rotondo et al. 2016). This anaerobic conversion of glucose to 3-carbon substrates (3C), was not related to hypoxia, since it took place in the presence of abundant oxygen. In addition, epididymal adipocytes from adult rats converted most of ${ }^{14} \mathrm{C}$-labelled glucose to labelled 3C Ho-Palma et al. 2018 in press).

The analysis of how a disperse organ (Vitali et al. 2012) in which the different sites play different functions, could maintain its distinctive organization and uniform control was one of the critical objectives of the present study. The objective was to find out whether the site differences were a question of adipocyte metabolic specialization within a frame of metabolic capabilities and parameters that define WAT as a specific (albeit disperse) organ. Consequently, we selected three quite different WAT sites: perigonadal (PG), mesenteric (MES) and subcutaneous (SC) WAT. PG, i.e. epididymal or periovaric, contains large cells, and a high percentage of fat per $\mathrm{g}$ of tissue (Romero et al. 2014); it is considered essentially an example of storage WAT (Ruan et al. 2003). In rats, MES WAT is less consistent, lax, and structurally complex in its connections, in part bridging the gap between intestine (and dietary nutrients) and the liver (Novelle et al. 2017). In humans, MES accounts for most of "visceral" WAT. SC WAT is even more diverse, with extreme differences between locations. Subcutaneous WAT is one of the most studied adipose tissues in humans (Gensanne et al. 2009) because of its accessibility. We used the inguinal fat pads, which provide a clearly distinguishable (and uniform) site with sufficient material for analysis.

In brief, our main objective in carrying this study was to test whether widely different (location, structure, fat content, blood flow, relationship with other organs, and median cell size) WAT sites shared a basic web of metabolic pathways, and, alternatively, showed distinct ways to handle energy substrates. The study was focused on the known relationships of glucose with lipogenesis, glycerogenesis, and especially, glycolysis to lactate (Sabater et al. 2014; Rotondo et 
115

116

117

118

119

120

121

122

123

124

125

126

127

128

129

130

131

132

133

134

135

136

137

138

139

140

141

142

143

al. 2017). We included sex as another potentially important variable, since most of our previous work had been done using males, and the sexual differentiation of adipose tissue metabolism plays a critical role in obesity and other metabolic syndrome pathologies (Medrikova et al. 2012).

\section{Materials and Methods}

Animals and sampling

The experimental design and the rat handling procedures were applied following the animal treatment guidelines established by the corresponding European, Spanish and Catalan Authorities. The Committee on Animal Experimentation of the University of Barcelona specifically authorized the procedures used in this study [Approval number: 9443].

Wistar rats (Janvier, Le Genest-Saint Isle, France), 14-week old (8 male and 8 female), were used after at least 7 days of adaptation to the new environment. The animals were kept in two-rat cages under standard conditions: i.e. $21.5-22.5^{\circ} \mathrm{C}$, and $50-60 \%$ relative humidity; lights were on from 08:00 to 20:00. The rats had free access to water and standard rat chow (\#2014, Teklad Diets, Madison WI USA) available in excess at any time.

When the females were in the proestrus phase, the rats were weighed, and killed at the beginning of a light cycle. After complete anesthesia using isoflurane, the animals were exsanguinated with syringes by puncturing the aorta. They were rapidly dissected, excising samples of mesenteric (MES) WAT, cleaned of attachments and pancreatic tissue, epididymal /periovaric (i.e. PG) WAT, and both inguinal pads of SC WAT.

\section{Experimental groups}

Tissue samples of a pair of same-sex rats with similar weight were coarsely minced and pooled prior to the separation of adipocytes. In all, four 2-rat samples were used for adipocyte extraction of each WAT site and sex. The cells were distributed in groups, incubated independently in at least four wells each (one for each pool of 2 rats of the same sex): The variables to study were: a) Sex: female and male. b) Site: SC, MES and PG. c) Initial glucose concentration: $7 \mathrm{mM}$ and $14 \mathrm{mM}$. And. d) time of incubation: $24 \mathrm{~h}$ or $48 \mathrm{~h}$. In total, there were 48 groups of four different rat pools. In all cases, at the end of the incubation, the cells were 
144 harvested and used for gene expression analysis, while the media were used for analysis of 145 glucose and metabolites as described below.

146 Preparation and incubation of adipocytes

147 Adipocytes were isolated by incubation with collagenase (type I \#LS004196, Worthington 148 Biomedicals, Lakewood, NJ USA), as described in a previous paper (Rotondo et al. 2016), 149 essentially following the Rodbell procedure (Rodbell 1964). Adipocyte numbers were counted 150 from the final washed suspensions. Their (spherical when free) diameters were measured using serial microphotographs (Figure 1) and the ImageJ software (http://imagej.nih.gov/ij/) (Baviskar 2011). The recovery of adipocytes with respect to the mass of WAT used was estimated in a number of randomly selected samples, as previously described (Rotondo et al. 2016). Incubations were carried out using 12-well plates (\#734-2324VWR International BVBA/Sprl., Leuven Belgium). The incubation medium consisted of $1.7 \mathrm{ml}$ of DMEM (\#11966-DMEM-no glucose; Gibco, Thermo-Fisher Scientific, Waltham MA USA), supplemented with, 30 mL/L fetal bovine serum (FBS, Gibco). The medium contained added glucose at a final nominal concentration of $7 \mathrm{mM}$ or $14 \mathrm{mM}$. The medium also contained $25 \mathrm{mM}$ hepes (Sigma-Aldrich, St Louis MO USA), 2mM glutamine (Lonza Biowhittaker, Radnor, PA USA), 1 mM pyruvate (Gibco), 30 mg/mL delipidated bovine serum albumin (Millipore Calbiochem, MA USA), 100 $\mathrm{nM}$ adenosine, $100 \mathrm{mU} / \mathrm{mL}$ penicillin and $100 \mathrm{mg} / \mathrm{L}$ streptomycin (all from Sigma-Aldrich).

Each well contained $400 \mu \mathrm{L}$ of the cell suspension. Since $0.1 \mathrm{~mL}$ of medium was used for initial measurements (metabolite zero values, cell counting), the final incubation volume was 2.0 $\mathrm{mL}$. The plates were kept at $37^{\circ} \mathrm{C}$ in an incubation chamber, ventilated with air supplemented with $5 \% \mathrm{CO}_{2}$. The cells were incubated for $24 \mathrm{~h}$ or $48 \mathrm{~h}$, without any further intervention, as previously described (Ho-Palma et al. 2016; Rotondo et al. 2016).

The incubation of adipocytes was stopped by pipetting out the whole contents of the well, allowing the adipocytes to float and form a defined layer, which was taken out. The infranatant medium was centrifuged (to recover any remaining adipocytes), mixed, aliquoted and frozen.

The media were used for the estimation of glucose, lactate, glycerol and NEFA. Glucose was measured using a glucose oxidase-peroxidase kit (\#11504, Biosystems, Barcelona Spain) containing 750 nkat/mL mutarrotase (porcine kidney, 136A5000, Calzyme, St Louis, MO USA) (Oliva et al. 2015). Lactate was measured with kit 1001330 (Spinreact, Sant Esteve d'en Bas, 
174 Spain); glycerol was estimated with kit \#F6428 (Sigma-Aldrich). NEFA were measured using kit

175 NEFA-HR (Wako Life Sciences, Mountain View, CA USA).

176 Gene expression analyses

177 Total cell RNA was extracted from the packed washed adipocytes using the Tripure 178 reagent (Roche Applied Science, Indianapolis IN USA), and were quantified using a ND-1000 179 spectrophotometer (Nanodrop Technologies, Wilmington DE USA). RNA samples were reverse 180 transcribed using the MMLV reverse transcriptase (Promega, Madison, WI USA) system and 181 oligo-dT primers. Real-time PCR (RT-PCR) amplification was carried out using $10 \mu \mathrm{L}$

182 amplification mixtures containing the Power SYBR Green PCR Master Mix (Applied Biosystems, Foster City, CA USA), 4 ng of reverse-transcribed RNA and $150 \mathrm{nM}$ primers. Reactions and measurement of evolved fluorescence were analyzed in an ABI PRISM 7900 HT detection system (Applied Biosystems),

A semi-quantitative approach for the estimation of the concentration of specific gene mRNAs per unit of tissue weight was used (Romero et al. 2007). Arbp was the charge control gene (Bamias et al. 2013). The results were expressed as the number of transcript copies per cell in order to obtain comparable data between the groups. The genes analyzed and a list of primers used are presented in Table 1.

\section{Statistics}

The experimental design combined two different animal origins of WAT (female, male), from three different anatomical locations (site: subcutaneous, mesenteric and perigonadal). In addition, the length of incubation ( $24 \mathrm{~h}$ or $48 \mathrm{~h}$ ) and the initial level of glucose ( $7 \mathrm{mM}$ or $14 \mathrm{mM})$. Since the effects of the parameters studied could influence the results in widely different ways, we tried to apply a escalating statistical comparison set up that will allow us to go from a general view to the specifics of which factors were more (or less) responsible for the differences. We considered that the intermixing of data could only be discerned using ANOVA analyses, since our experimental design had low $\mathrm{N}$ values, because of the need for integral comparison of data and cooperative analysis in the individual wells,. Thus, we scaled the statistical analyses between groups using four-, three- or two-way ANOVAs on the same sets of data. Analyses were carried out with the Stratgraphics program (Statpoint Technologies, Warrington, VA USA). 


\section{Results}

205 Cells, glucose uptake and metabolite efflux

206 Mean adipocyte volumes for the suspensions of cells used are shown in Figure 1. There 207 were significant differences for site (but not for sex) in mean cell size; the largest cells were 208 those of PG WAT. We expressed the metabolite efflux (or uptake in the case of glucose) as rates 209 akin to the unit of enzyme activity, katal, and taking the cell as unit for comparison.

210 Consequently, the data (shown in Figure 2) were expressed as attomoles per second and cell. 211 Data were analyzed using ANOVAs, four way, as indicated in the legend of the Figure, three 212 way, independently for each site, and two-way for sex in each site (both series shown in the 213 Figure itself).

214 Four-way ANOVA showed the general trend: there were differences between sites 215 affecting all parameters; sex also showed significant differences for everything except lactate 216 efflux. On the other side, doubling glucose concentration only affected glucose uptake, whereas 217 the time of incubation affected all parameters except glucose uptake. The latter parameter was 218 closely linked to the incubation time, with limited effects of sex (except in PG WAT).

219 Lactate efflux was remarkably uniform and not related to glucose concentration or the 220 time of incubation (except in PG WAT), but there was an overall significant effect of sex on SC WAT (not observed in the other sites). Glycerol and NEFA efflux showed a similar pattern, despite glycerol efflux being, in all cases, much larger than that of NEFA. There was a significant effect of sex in all WAT sites (except for NEFA in PG WAT), and a practically nil effect of glucose concentration. However, the duration of incubation markedly raised the efflux of both glycerol and NEFA in all sites, irrespective of sex, the sole exception being adipocytes of MES WAT from females, which were unaffected by glucose and/or incubation time. Glycerol efflux (and NEFA to a lower extent) by MES cells was higher than those of SC or PG cells. Analysis of gene expression

We used the same statistical comparative approach described above for metabolites to analyze the changes in gene expression at 24 and $48 \mathrm{~h}$ of incubation. Here we present the data as number of copies of the gene mRNA transcripts per cell. Figures 3 to 6 show the gene expressions of main enzymes and transporters affecting the metabolism of glucose, lipogenesis and $3 \mathrm{C}$ fragment handling in the adipocyte. The statistical analysis of the differences between 
234 groups, related to WAT sites, sexes and the medium glucose concentration were shown in the

235

236

237

238

239

240

241

242

243

244

245

246

247

248

249

250

251

252

253

254

255

256

257

258

259

260

261

262

263

264 graphs and Figure legends. The presentation -and initial analysis- of the gene expression data was done along three main lines: a) Glucose and glycerol, b) Fatty acid metabolism, c) Pyruvate, lactate and oxaloacetate. Figure 7 shows a schematic view of the genes studied. superimposed to the main metabolic pathways of carbohydrate-lipid relationships in the adipocyte.

a) Glucose and glycerol

In MES, the expression of Glut1 was higher in males than in females; it was practically unaltered by glucose and incubation time. In SC WAT, the Glut1 expression was lower than in the other sites. Males showed a marked interaction between glucose level and incubation time. The expression of $H k 1$ repeated the trend of Glut1, but in MES WAT, the effects of sex were more marked, with male-origin adipocytes decreasing their gene expression with incubation time. Sex differences were more marked in $P f k l$, repeating the pattern of higher male expression in MES and lower in PG WAT; no effect of glucose levels were observed, either, but incubation time increased the expression of this gene, especially in PG WAT. The expressions of Phgdh (not a pathway control enzyme) were rather uniform, and lower than the other glycolytic enzymes analyzed. There was a trend to increase expression with incubation time, and to maintain the male-female predominance described for the other enzymes, but variability was high and the statistical significance of the differences was low. In sum, no marked changes were found to be influenced by the conditions of the study, suggesting a fluid and uniform operation of glycolysis down to pyruvate with practically no effects of external glucose concentration, combined with increased expressions with incubation time.

Glycerol efflux was paralleled by a marked trend to increase the already high expression of Gpdl (i.e. compared with Phgdh) with incubation time, but -again-it was not affected by the concentration of glucose. The maximal increase in expression, not linked to sex, was observed in PG WAT. The phosphatase pathway ( $P g p$ ) showed no changes at all, except for higher values in females of its (also high) expression in PG WAT. This was not the case for the enzyme catalyzing the reverse reaction, glycerokinase, which gene $(G k)$ maintained the differences between sexes, but showed a higher increase of its expression with incubation time. The overall number of copies per cell of $G k$ was, however, about one order of magnitude lower than that of $P g p$. The patterns for Aquaporin 7 gene ( $A q p 7$ ) expression closely resembled those of Pgp, including the range of copies per cell. 
The assumed incorporation of newly formed glycerol-3P into acyl-glycerols increased with

266

267

268

269

270

271

272

273

274

275

276

277

278

279

280

281

282

283

284

285

286

287

288

289

290

291

292

293

incubation time, judging from the expression of Gpam, following a pattern comparable to that of Gpd1, deeply affected by time but not by medium glucose levels. Sex differences were maintained: higher values for females in SC, and, especially, PG WAT. and higher levels of expression for males in MES.

\section{b) Fatty acid metabolism}

Lipogenesis did not seem to represent a quantitatively important process under the conditions tested because of the limited possibility of producing acetyl-CoA from the main medium substrate, glucose (down to pyruvate). Pyruvate dehydrogenase activity may be hampered, both because of the relatively scarce number of mitochondria and because of the proportionally high expression of the main controller of the enzyme, pyruvate dehydrogenase kinase 4. The expression of its gene (Pdk4) showed a marked effect of incubation time, increasing (in all three sites) differently according to sex. Males and females' Pdk4 expression in SC and PG WAT increased about one order of magnitude in $24 \mathrm{~h}$. In MES WAT, males followed the same pattern, but no significant increase with incubation time was observed in females (despite its spectacular rise in PG WAT). Under these conditions, pyruvate dehydrogenase could not operate fully at $48 \mathrm{~h}$, but these effects should be less marked in the MES WAT of females.

The transfer of acetyl-CoA to the cytoplasm via citrate: ATP lyase was not affected by the treatment received by adipocytes, as shown by the little change found in the expression of its gene Acly. Carboxylation of acetyl-CoA to malonyl-CoA was probably unchanged (or decreased in male adipocytes of MES WAT) from the expression of Acaca. A similar pattern, with higher number of copies per cell, was observed in Fas, fatty acid synthase. As for the availability of NADPH in the cytoplasm, the indicator gene of the pentose phosphate pathway G6pdx showed high numbers of copies and a marked sexual differentiation in MES and PG WAT, but no changes induced by glucose or incubation time. These data suggest an absence of change in the main NADPH provider, in parallel to the glycolytic and pyruvate-handling pathways already analyzed. The other main NADPH generator, malic enzyme (Mel), also showed little change in its expression, with a tendency to lower the number of copies in MES-WAT with incubation time. 
Probably, the uptake of medium fatty acids (at least from cell remnants), was activated,

295

296

297

298

299

300

301

302

303

304

305

306

307

308

309

310

311

312

313

314

315

316

317

318

319

320

321

322

323

324

since the expression of one of the main transporters $C d 36$ increased with time. Sex affected only PG WAT, and no effects of glucose levels were observed at all. Mitochondrial utilization of acyl-CoA was assumed to be low (if any), first because of the nature of the tissue and its energy needs (expected low oxidative metabolism); second because of the ample availability of glucose; and third because the expression of $C p t 1 b$ was very low in all three sites, thus making difficult the entry of acyl-CoA into the mitochondria. The already described differences related to sex were maintained, and there was a marked increase with time in the expression of this gene in both sexes.

The main lipases of adipose tissue: the extracellular lipoprotein lipase $(L p l)$, and the internal adipose TAG lipase $(A \operatorname{tgl})$ and hormone-sensitive lipase $(H s l)$ showed essentially the same trend. All had uniform increases in gene expression with incubation time, lack of effects of glucose and sex-related differences of limited extent. $L p l$ showed the highest number of copies per cell found in this study. In the case of MES WAT, females' increase of expression with time was less marked than that of males, a reminiscence of the discordance described for Pdk4. The high coordinated increase in lipase activity was not correlated to the limited release of NEFA into the medium, and these levels were far from being correlated with any of the expressions of the lipases studied.

\section{c) Pyruvate, lactate and oxaloacetate}

In addition to the different sex-related response of $P d k 4$ expression of adipocytes with incubation, further limiting the synthesis of acetyl-CoA in most of the conditions analyzed, the obviously major outlet for excess pyruvate generation in the cytoplasm was its conversion to lactate, completing the classic glycolytic pathway. The number of copies of Ldha was high, with practically no effect of sex, but showing a trend to increase its expression with time of incubation in SC and PG WAT. Initial glucose affected more intensely the MES values, decreasing Ldha expression at lower-, and increasing at higher medium glucose, with a clear differentiation by sex (higher values for males). Ldhb showed less change and lower number of copies per cell. The ratio of expression of both lactate dehydrogenase isoform genes ( $L d h a / L d h b)$ was rather constant, with a mean value of 6.2 for both sexes. The expression of the monocarboxylate transporter gene (Mct l) presented a pattern closely similar to that of $L d h a$, hinting at a coordinated regulation. As described above, Mel showed only limited changes in expression, 
325

326

327

328

329

330

331

332

333

334

335

336

337

338

339

340

341

342

343

344

345

346

347

348

349

350

351

352

353

354

355

which agrees with the lower needs for NADPH (mainly used for lipogenesis) observed under the conditions of incubation. Last, but not least, the key marker enzyme gene Pckl (P-enol-pyruvate carboxy-kinase), a critical enzyme bridging the pyruvate kinase gap to favor the arrival of oxaloacetate to the triose-P pool under conditions of scarcity of glucose, showed a marked sexrelated difference in its response to incubation. Irrespective of glucose concentration, both sexes in PG and only males in SC and MES WAT increased dramatically its expression with time of incubation, suggesting the need for the conversion of excess cytoplasmic oxaloacetate into Penol pyruvate. This change was not observed in female adipocytes of SC and MES WAT, in a pattern closely resembling that of MES Pdk4.

\section{Discussion}

The main outcome of this study is a reinforcement of the widely accepted idea that WAT sites are remarkably uniform (Arriarán et al. 2015b) from a qualitative point of view, but also that they are adjusted to play different metabolic functions depending on their location (PrunetMarcassus et al. 2006). Thus, the differences between sites were mainly quantitative. This idea is not new, but the comparative analyses of the capacity of metabolic pathways are too scarce and incomplete to provide sufficient support. Our contribution may help reinforce the assumption that WAT plays a role in glucose handling, sufficient to participate in the maintenance of glycaemia (Arriarán et al. 2015b; Ho-Palma et al. 2016). We also present additional evidence that key metabolic functions of WAT are deeply affected by sex, as previously indicated (Amengual-Cladera et al. 2012; White \& Tchoukalova 2014). This aspect is more clearly observed in MES and SC WAT than in the fat pads (PG) attached to reproductive organs. Our data also agree with the postulated role of glycolysis to lactate as main provider of energy (ATP) to sustain most of the white adipocyte normal function (Crandall et al. 1983; Hagström et al. 1990; Sabater et al. 2014), thus reducing its need for oxidative metabolism, and, consequently, of oxygen (Sjöström 1990). This aspect is also sustained, by the WAT relative scarcity of mitochondria and, logically, of the oxidative metabolism they sustain (Deveaud et al. 2004; Frayn et al. 2008). We assume that glucose is taken up as needed (mainly for energy); and, consequently, lactate is released not as a response to glucose availability (and uptake) but depending on cytoplasm energy requirements. The consequence is an extensive conversion of glucose to $3 \mathrm{C}$ metabolites because of the energetic inefficiency of the (anaerobic) glycolytic use 
356 of glucose. The $3 \mathrm{C}$ thus generated can be easily used for energy or as carbon source elsewhere 357 (Frayn \& Coppack 1990; Sabater et al. 2014; Arriarán et al. 2015c; Rotondo et al. 2017b).

358 Our previous studies on adipocyte primary cultures were carried out using only male rats' epididymal adipose tissue (Rotondo et al. 2017b), a classical depot WAT site; the comparison done here with female rat periovaric WAT showed little differences between them, even with respect to potential fatty acid synthesis. These results were not expected, given the higher tendency to fat accumulation of adult males versus females, both in rats and humans (Schemmel et al. 1969; Fried et al. 2015). However, as a rule, the number of copies per cell for most of the genes studied was higher in females than in males, in contrast with the smaller (NS) mean size of their adipocytes, hinting at a possibly higher overall metabolic activity of female WAT (Blaak 2001).

MES WAT showed a markedly higher efflux of glycerol, and NEFA (to a proportionally lower extent in molar terms), compared with the other sites investigated. Previous analyses of glucose carbon fate in epididymal WAT showed that a sizeable proportion of glucose ended forming part of glyceride-glycerol (Cahill et al. 1959; Ho-Palma et al. 2016). Results were more marked after incubation of adipocytes for more than one day in the presence of glucose (Rotondo et al. 2017b).There was, also, a significant lipase-driven TAG turnover, in which most of fatty acids were recycled to TAG (Hammond \& Johnston 1987), but glycerol was excreted (Vaughan 1962; Jansson et al. 1992). The data of the present study agree with this interpretation. However, since no labelled $\mathrm{C}$ has been used, we can only deduce (not prove) the origin of glycerideglycerol in the adipocytes. We know, however, that the rates of glycerol release to the medium by MES were much higher than in PG WAT (both epididymal and periovaric). We can, assume, thus, that glycerol production in MES WAT may be higher than that of the only tissue quantitatively analyzed in detail with tracers, male PG WAT (Ho-Palma et al. 2016). Since MES WAT plays an ancillary energy-handling role to the liver, its massive production of glycerol (to our knowledge not previously described) may help facilitate the hepatic handling of fatty acids. Intestinal absorption-derived fatty acids, not used in the synthesis of the TAG carried out by lymph, as well as excess systemic blood NEFA arrived to the liver mixed in the portal blood with the efflux of MES-WAT. This WAT site may also help to lower the portal intestine-released glucose load carried to the liver, as shown by the higher glucose uptake and $3 \mathrm{C}$ substrate efflux 386 rates in MES when compared with SC and, especially, PG WAT. We can speculate that MES- 
387 WAT activity may help buffer the impact of large digestive glucose loads, and thus facilitate its 388 hepatic handling.

389 The differences in response between female- and male-derived MES adipocytes facing 390 periodic exposure to excess energy (in this case, glucose) seem minimal, but may be farreaching. In addition to higher overall glycerol efflux, in female rats, pyruvate dehydrogenase inhibition by its kinase 4 seems not to be altered by either glucose levels or time of incubation. This occurs in contrast with the high increases elicited in males (Rotondo et al. 2017b) of the number of copies of Pdk4, a powerful inhibitor of the dehydrogenase (Cadoudal et al. 2008), which is mainly regulated via transcription (Jeong et al. 2012). This increase was also observed in SC and PG WAT of both male and female rats, being, thus, a unique effect restricted to (female) MES WAT. This assumed "lower potential inhibition" of pyruvate dehydrogenase hints at a potentially higher flow of 3C (pyruvate) into mitochondrial acetyl-CoA, thus facilitating either its oxidation or incorporation into the lipogenic pathway. This could not proceed so easily in males (or in other WAT sites of females), which Pdk4 expression increased with time and exposure to glucose, preventing the decarboxylation of mitochondrial pyruvate to acetyl-CoA. Since in female MES, excess mitochondrial pyruvate could not be processed to acetyl-CoA, it must be returned to the cytosol. The limitation of mitochondrial acetyl-CoA means that it could not be derived through the Krebs cycle, which in any case needs oxygen to oxidize it. Thus, the most probable way of utilization of the 'surplus' mitochondrial pyruvate is via carboxylation (Ballard \& Hanson 1967) to oxaloacetate and its transfer to the cytoplasm via the pyruvate/malate shuttle, partly using the machinery of fatty acid synthesis (Patel et al. 1971). This implies a considerable activity of the malate-oxaloacetate metabolism in the mitochondria, albeit not implicating citrate. After malate is transferred into the cytosol, it could be either used by the malic enzyme to provide NADPH (improbable in this case as explained above) or oxidized to oxaloacetate by the cytoplasmic malate dehydrogenase, providing NADH (Nye et al. 2008). Cytoplasmic oxaloacetate can be converted into P-enol-pyruvate by its carboxy-kinase (Ballard et al. 1967). In males, the expression of its gene, $P c k 1$, was raised with incubation time in parallel to $P d k 4$, but it was stabilized in females following the same pattern than the kinase, an effect extended to SC-WAT. The differences in the cytosol-mitochondria handling of pyruvate suggest a deep sex-related divergence in the metabolic fate of pyruvate, which, ultimately, may 
417 help explain the known different metabolic handling of lipids (and, probably glucose) by visceral

418 WAT depending on sex (Franckhauser et al. 2002).

419 Curiously, the alternatives for disposal of the oxaloacetate assumedly extracted from the

420

421

422

423

424

425

426

427

428

429

430

431

432

433

434

435

436

437

438

439

440

441

442

443

444

445

446

447

mitochondria by the malate shunt point to the regeneration of P-enol pyruvate. This high-energy compound could not go further up the glycolytic pathway because of massive thrust of glycolysis carbon flow towards pyruvate/lactate. The high lactate efflux is proof of the unequivocal direction of glycolysis in the adipocytes, at least under the conditions and cell sizes used in this study, leaving open only the conversion (again) of P-enol-pyruvate to pyruvate by pyruvate kinase. However, the difference (in females) lies, precisely, in the assumed provision of cytoplasmic NADH by malate dehydrogenase, which may provide reducing power for the final conversion of pyruvate to lactate (Rotondo et al. 2017b) easing its disposal via excretion.

Since pyruvate is a good substrate for lipogenesis (Schmidt \& Katz 1969) and WAT is the largest depot for body lipid storage, one can expect lipogenesis to be fully activated when glucose availability is high. The process requires, however, the massive production of acetylCoA, its transfer to the cytoplasm via citrate and then a full activation of lipogenesis, including necessarily higher expressions of Acaca and Fas and the activation of NADPH providers (such as G6pdx or Mel). None of these signs was detected; no effects of glucose or duration of the incubation affected the expressions of these genes. Probably, quantitative conversion of glucose to fatty acids under high glucose conditions was not as a function as relevant for the adipocyte (or WAT) as to dispose of excess glucose, in agreement with previous studies using labelled glucose (Rotondo et al. 2017b).

In addition to the paradoxical apparent inactivity of lipogenesis, there was a high increment with time (but not with higher glucose) of lipase gene $\mathrm{Lpl}$ and $\mathrm{Atgl}$ expressions (in $\mathrm{Hsl}_{s}$ we observed a tendency to "restraint" resembling those of Pdk4 and Pck1) (Sabater et al. 2014; Rotondo et al. 2016; Rotondo et al. 2017b). However, the expected massive efflux of NEFA did not occur. In any case, NEFA were released to the medium in much smaller proportions than the canonical 3-to-1 molar ratio vs. glycerol expected from TAG hydrolysis, in disagreement with the frank liberation of NEFA described for the initial phase of catecholamine-elicited WAT lipolysis (Jocken et al. 2008). The results shown here were, however, fully compatible with an activation of TAG turnover, a critical adipocyte regulatory system (Arner et al. 2011). In the end, this process, selectively released glycerol as a $3 \mathrm{C}$ substrate ultimately derived from glucose, as 
448 we have previously established (Arriarán et al. 2015c; Rotondo et al. 2017b). The highest

449 number of lipase gene mRNA copies per cell, and the steepest increase with time was observed 450 in PG WAT (Rotondo et al. 2016; Rotondo et al. 2017b), with values even higher for females as 451 found in the present study. Nevertheless, the glycerol release rates observed for this site were 452 smaller than in MES and SC WAT.

453 The higher female number of copies for $G k$ (glycerol kinase gene) may suggest the 454 existence of an additional restrain of the whole process, i.e. free glycerol being recycled to $s n$ 455 glycerol-3P (Lee et al. 2005). This process may potentially decrease the actual release of 456 glycerol, in parallel to lower NEFA liberation. It can unbalance, also, the equilibrium between 457 glycerol-3P synthesis and hydrolysis (Margolis \& Vaughan 1962). However, we have not 458 sufficient data to prove or disprove the operation of this alternative pathway, which would help define the postulated increase in WAT turnover as a 'futile cycle' in which energy was wasted 460 (for thermogenesis?).

WAT production of glycerol has been known for a long time (Vaughan 1962; van der Merwe et al. 1998; Bolinder et al. 2000). Glycerol has been related to glucose in WAT as source of carbon (Wood et al. 1960; Smith 1972), but its immediate origin has been linked to lipolysis (Karpe et al. 2005; Langin 2006) within the context of the glucose-fatty acid cycle (Randle et al. al. 2008). The quantitative approach used here shows that there is a direct relationship between glycerol and NEFA release, but not at the ratios expected, and points to lipolysis as part of TAG turnover. This turnover was accelerated with time, apparently to favor the release of more glycerol. Nevertheless, the main factor affected by these changes, and that most modulated by sex (at least in MES adipocytes) was assumed to be the equilibrium between NADPH and $\mathrm{NADH}$ in the thin layer of adipocyte cytoplasm. Intercellular cooperation, perhaps close

472 neighboring cells, smaller than adipocytes, providers of mitochondria oxidative power, are 473 needed to fully understand how WAT works, and, also, to uncover the intricate effects of sex on 474 WAT operation (Randle et al. 1963).

475

\section{Conclusions}


478 changes, and the actually small amount of "live matter" in the adipocytes used in the incubations

479 hint at an active but stabilized energy sustaining machinery working along the 2-day incubation.

480 This resulted in a high proportion of glucose converted to $3 \mathrm{C}$ substrates, largely lactate. The

481 length of the incubation period modulated the development and timing of the alternative

482 mechanisms that allow the synthesis and release of free glycerol, especially addressed to the liver

483 (at least by the highest WAT glycerol producer, the MES site), and the considerable restraint

484 observed in the synthesis of fatty acids in the presence of high medium glucose concentrations.

485 These findings are not completely new, but its concatenation is.

486 In fact, the resilience of adipocytes to limit the production of additional fatty acids under

487 excess glucose availability, breaking up, instead, most of the glucose, then released as lactate and

488 glycerol, is remarkable. It also makes us wonder whether we can keep considering true the

489 current assumption that WAT 'has to take up and use for fat synthesis the surplus dietary

490 glucose', under conditions of excess glucose/energy available (a principle often used to help

491 explain obesity).

492

493

494

\section{References}

Ailhaud G, Amri E, Bardon S, Barcellinicouget S, Bertrand B, Catalioto RM, Dani C, Doglio A, Forest C, Gaillard D, Grimaldi P, Ibrahimi A, Negrel R, Vannier C, and Vassaux G. 1991. Growth and Differentiation of Regional Adipose-Tissue - Molecular and Hormonal Mechanisms. International Journal of Obesity 15:87-90.

Alemany M. 2011. The defense of adipose tissue against excess substrate-induced hyperthrophia: Immune system cell infiltration and arrested metabolic activity. Journal of Clinical Endocrinology and Metabolism 96:66-68.

Am Ailhaud G, Amri E, Bardon S, Barcellinicouget S, Bertrand B, Catalioto RM, Dani C, Doglio A, Forest C, Gaillard D, Grimaldi P, Ibrahimi A, Negrel R, Vannier C, and Vassaux G. 1991. Growth and Differentiation of Regional Adipose-Tissue - Molecular and Hormonal Mechanisms. International Journal of Obesity 15:87-90. 
505 506 507 508 509 510 511 512

Amengual-Cladera E, Lladó I, Gianotti M, and Proenza AM. 2012. Sex differences in the effect of high-fat diet feeding on rat white adipose tissue mitochondrial function and insulin sensitivity. Metabolism-Clinical and Experimental 61:1108-1117.

Arner P, Bernard S, Salehpour M, Possnert G, Liebl J, Steier P, Buchholz BA, Eriksson M, Arner E, Hauner H, Skurk T, Ryden M, Frayn KN, and Spalding KL. 2011. Dynamics of human adipose lipid turnover in health and metabolic disease. Nature 478:110-113.

Arriarán S, Agnelli S, Remesar X, Fernández-López J-A, and Alemany M. 2015a. The urea cycle of rat white adipose tissue. RSC Advances 5:93403-93414. 10.1039/c5ra16398f

Arriarán S, Agnelli S, Remesar X, Fernández-López JA, and Alemany M. 2015b. Effects of sex and site on amino acid metabolism enzyme gene expression and activity in rat white adipose tissue. PeerJ 3:e1399. 10.7717/peerj.1399

Arriarán S, Agnelli S, Sabater D, Remesar X, Fernández-López JA, and Alemany M. 2015c. Evidences of basal lactate production in the main white adipose tissue sites of rats. Effects of sex and a cafeteria diet. PloS One 10:e0119572. 10.1371/journal.pone.0119572

Ballard F, Hanson RW, and Leveille G. 1967. Phosphoenolpyruvate carboxykinase and the synthesis of glyceride-glycerol from pyruvate in adipose tissue. Journal of Biological Chemistry 242:2746-2750.

Ballard FJ, and Hanson RW. 1967. The citrate cleavage pathway and lipogenesis in rat adipose tissue: replenishment of oxaloacetate. Journal of Lipid Research 8:73-79.

Bamias G, Goukos D, Laouidi E, Balla IG, Siakavellas SI, Daikos GL, and Ladas SD. 2013. Comparative study of candidate housekeeping genes for quantification of target gene messenhgar RNA expression by real-time PCR in patients with inflammatory bowel disease. Inflammatory Bowel Diseases 19:2840-2847.

Baviskar SN. 2011. A quick \& automated method for measuring cell area using ImageJ. American Biology Teacher 73:554-556.

Blaak E. 2001. Gender differences in fat metabolism. Current Opinion in Clinical Nutrition and Metabolic Care 4:499-502. 
532 Bolinder J, Kerckhoffs DAJM, Moberg E, Hagström-Toft E, and Arner P. 2000. Rates of skeletal 533 muscle and adipose tissue glycerol release in nonobese and obese subjects. Diabetes $534 \quad 49: 797-802$.

535 Cadoudal T, Distel E, Durant S, Fouque F, Blouin JM, Collinet M, Bortoli S, Forest C, and Benelli 536 C. 2008. Pyruvate dehydrogenase kinase 4 regulation by thiazolidinediones and implication in glyceroneogenesis in adipose tissue. Diabetes 57:2272-2279.

538

539

540

541

542

543

544

545

546

547

548

549

550

551

552

553

554

555

556

557

558

559

560

Cahill GF, Leboeuf B, and Renold AE. 1959. Studies on rat adipose tissue in vitro : III. Synthesis of glycogen and glyceride-glycerol. Journal of Biological Chemistry 234:2540-2543.

Cancello R, and Clément K. 2006. Is obesity an inflammatory illness? Role of low-grade inflammation and macrophage infiltration in human white adipose tissue. British Journal of Obstetrics and Gynaecology 113:1141-1147.

Cinti S. 2005. The adipose organ. Prostaglandins Leukotrienes and Essential Fatty Acids 73:9-15.

Crandall DL, Fried SK, Francendese AA, Nickel M, and DiGirolamo M. 1983. Lactate release from isolated rat adipocytes: Influence of cell size, glucose concentration; insulin and epinephrine. Hormone and Metabolic Research 15:326-329.

Deveaud C, Beauvoit B, Salin B, Schaeffer J, and Rigoulet M. 2004. Regional differences in oxidative capacity of rat white adipose tissue are linked to the mitochondrial content of mature adipocytes. Molecular and Cellular Biochemistry 267:157-166.

Franckhauser S, Muñoz S, Pujol A, Casellas A, Riu E, Otaegui P, Su B, and F. B. 2002. Increased fatty acid re-esterification by PEPCK overexpression in adipose tissue leads to obesity without insulin resistance. Diabetes 51:624-630.

Frayn KN, and Coppack SW. 1990. Evidence for lactate production by human adipose tissue in vivo. Diabetologia 33:740-740.

Frayn KN, Langin D, and Karpe F. 2008. Fatty acid-induced mitochondrial uncoupling in adipocytes is not a promising target for treatment of insulin resistance unless adipocyte oxidative capacity is increased. Diabetologia 51:394-397.

Fried SK, Lee MJ, and Karastergiou K. 2015. Shaping fat distribution: New insights into the molecular determinants of depot- and sex-dependent adipose biology. Obesity 23:13451352. 10.1002/oby. 21133 
561 Gensanne D, Josse G, Theunis J, Lagarde JM, and Vincensini D. 2009. Quantitative magnetic

562

563

564

565

566

567

568

569

570

571

572

573

574

575

576

577

578

579

580

581

582

583

584

585

586

587

588 resonance imaging of subcutaneous adipose tissue. Skin Research and Technology 15:4550.

Giralt M, and Villarroya F. 2013. White, brown, beige/brite: different adipose cells for different functions? Endocrinology 154:2992-3000.

Greif M, von Ziegler F, Wakili R, Tittus J, Becker C, Helbig S, Laubender RP, Schwarz W, d'Anastasi M, Schenzle J, Leber AW, and Becker A. 2013. Increased pericardial adipose tissue is correlated with atrial fibrillation and left atrial dilatation. Clinical Research in Cardiology 102:555-562.

Guzik TJ, Marvar PJ, Czesnikiewicz-Guzik M, and Korbut R. 2007. Perivascular adipose tissue as a messenger of the brain-vessel axis: Role in vascular inflammation and dysfunction. Journal of Physiology and Pharmacology 58:591-610.

Hagström E, Arner P, Ungerstedt U, and Bolinder J. 1990. Subcutaneous adipose tissue: a source of lactate production after glucose ingestion in humans. American Journal of Physiology 258:E888-E893.

Hammond VA, and Johnston DG. 1987. Substrate cycling between triglyceride and fatty acid in human adipocytes. Metabolism 36:308-313.

Ho-Palma AC, Rotondo F, Romero MM, Memmolo S, Remesar X, Fernández-López JA, and Alemany M. 2016. A method for the measurement of lactate, glycerol and fatty acids production from ${ }^{14} \mathrm{C}$-glucose in primary cultures of rat epididymal adipocytes. Analytical Methods 8:7873-7885. 10.1039/c6ay01244b

Ho-Palma AC, Rotondo F, Romero MM, Fernández-López JA, Remesar X and Alemany M. 2018. Use of ${ }^{14} \mathrm{C}$-glucose by primary cultures of mature rat epididymal adipocytes. Marked release of lactate and glycerol, but limited lipogenesis in the absence of external stimuli. Adipocyte in press. 10.1080/21623945.2018.1460020

Jamdar SC. 1978. Glycerolipid biosynthesis in rat adipose tissue. Influence of adipose cell size and site of adipose tissue on triacylglicerol formation in lean and obese rats. Biochemical Journal 170:153-160. 
589 Jansson PA, Larsson A, Smith U, and Lönnroth P. 1992. Glycerol production in subcutaneous $590 \quad$ adipose tissue of lean and obese humans. Journal of Clinical Investigation 89:1610-1617.

591 Jeong JY, Jeoung NH, Park KG, and Lee IK. 2012. Transcriptional regulation of pyruvate 592 dehydrogenase kinase. Diabetes and Metabolism Journal 36:328-335.

593 594 595 596

Jocken JWE, Goossens GH, van Hees AMJ, Frayn KN, van Baak M, Stegen J, Pakbiers MTW, Saris WHM, and Blaak EE. 2008. Effect of beta-adrenergic stimulation on whole-body and abdominal subcutaneous adipose tissue lipolysis in lean and obese men. Diabetologia $51: 320-327$.

Kaplan NM. 1989. The deadly quartet. Upper-body obesity, glucose intolerance, hypertriglyceridemia and hypertension. Archives of Internal Medicine 149:1514-1520.

Karpe F, Fielding BA, Coppack SW, Lawrence VJ, Macdonald IA, and Frayn KN. 2005. Oscillations of fatty acid and glycerol release from human subcutaneous adipose tissue in vivo. Diabetes 54:1297-1303.

Kershaw EE, and Flier JS. 2004. Adipose tissue as an endocrine organ. Journal of Clinical Endocrinology and Metabolism 89:2548-2556.

Kopecký J, Rossmeisl M, Flachs P, Brauner P, Sponarová J, Matejková O, Prazak T, Ruzicková J, Bardová K, and Kuda O. 2004. Energy metabolism of adipose tissue - Physiological aspects and target in obesity treatment. Physiological Research 53:S225-S232.

Kuk JL, Lee SJ, Heymsfield SB, and Ross R. 2005. Waist circumference and abdominal adipose tissue distribution: influence of age and sex. American Journal of Clinical Nutrition 81:1330-1334.

Langin D. 2006. Control of fatty acid and glycerol release in adipose tissue lipolysis. Comptes Rendus Biologies 329:598-607.

Lee D-H, Park D-B, Lee Y-K, An C-S, Oh Y-S, Kang J-S, Kang S-H, and Chung M-Y. 2005. The effects of thiazolidinedione treatment on the regulations of aquaglyceroporins and glycerol kinase in OLETF rats. Metabolism 54:1282-1289.

Luche E, Sengenès C, Arnaud E, Laharrague P, Casteilla L, and Cousin B. 2015. Differential hematopoietic activity in white adipose tissue depending on its localization. Journal of Cellular Physiology 230:3076-3083. 10.1002/jcp.25045 
618 Margolis S, and Vaughan M. 1962. $\square$-Glycerophosphate synthesis and breakdown in homogenates 619 of adipose tissue. Journal of Biological Chemistry 237:44-48.

620 Medrikova D, Jilkova ZM, Bardova K, Janovska P, Rossmeisl M, and Kopecky J. 2012. Sex 621 differences during the course of diet-induced obesity in mice: adipose tissue expandability 622 and glycemic control. International Journal of Obesity 36:262-272.

Novelle MG, Vázquez MJ, Peinado JR, Martinello KD, López M, Luckman SM, Tena-Sempere 624 M, Malagón MM, Nogueiras R, and Diéguez C. 2017. Sequential exposure to obesogenic factors in females rats: From physiological changes to lipid metabolism in liver and mesenteric adipose tissue. Scientific Reports 7:46194. 10.1038/srep46194

Nye C, Kim J, Kalhan SC, and Hanson RW. 2008. Reassessing triglyceride synthesis in adipose tissue. Trends in Endocrinology and Metabolism 19:356-361.

Oliva L, Baron C, Fernández-López J-A, Remesar X, and Alemany M. 2015. Marked increase in rat red blood cell membrane protein glycosylation by one-month treatment with a cafeteria diet. PeerJ 3:e1101. 10.7717/peerj.1101

Patel MS, Jomain-Baum M, Ballard FJ, and Hanson RW. 1971. Pathway of carbon flow during 633 fatty acid synthesis from lactate and pyruvate in rat adipose tissue. Journal of Lipid Research 12:179-191.

Pou KM, Massaro JM, Hoffmann U, Vasan RS, Maurovich-Horvat P, Larson MG, Keaney JF, 636 Meigs JB, Lipinska I, Kathiresan S, Murabito JM, O'Donnell CJ, Benjamin EJ, and Fox CS. 2007. Visceral and subcutaneous adipose tissue volumes are cross-sectionally related

Power ML, and Schulkin J. 2008. Sex differences in fat storage, fat metabolism, and the health risks from obesity: possible evolutionary origins. British Journal of Nutrition 99:931-940. to markers of inflammation and oxidative stress. The Framingham Heart Study. Circulation 116:1234-1241.

645

Qiu YF, Shan B, Yang L, and Liu Y. 2016. Adipose tissue macrophage in immune regulation of 646 metabolism. Science China-Life Sciences 59:1232-1240. 10.1007/s11427-016-0155-1 
647 Randle PJ, Garland PB, Hales CN, and Newsholme EA. 1963. The glucose fatty-acid cycle: its

648

649

650

651

652

653

654

655

656

657

658

659

660

661

662

663

664

665

666

667

668

669

670

671

672

673

674

675 role in insulin sensitivity and the metabolc disturbances of diabetes mellitus. Lancet 281:785-789.

Ribeiro Silva K, Côrtes I, Liechocki S, Ivar Carneiro JR, Peixoto Souza AA, Borojevic R, Menezes Maya-Monteiro C, and Santos Baptista L. 2017. Characterization of stromal vascular fraction and adipose stem cells from subcutaneous, preperitoneal and visceral morbidly obese human adipose tissue depots. PloS One 12:e0174115. 0.1371/.pone.0174115

Rodbell M. 1964. Metabolism of isolated fat cells. I. Effects of hormones on glucose metabolism + lipolysis. Journal of Biological Chemistry 239:375-380.

Romero MdM, Roy S, Pouillot K, Feito M, Esteve M, Grasa MdM, Fernández-López J-A, Alemany M, and Remesar X. 2014. Treatment of rats with a self-selected hyperlipidic diet, increases the lipid content of the main adipose tissue sites in a proportion similar to that of the lipids in the rest of organs and tissues. PloS One 9:e0090995.10.1371/ journal.pone.0090995

Romero MM, Grasa MM, Esteve M, Fernández-López JA, and Alemany M. 2007. Semiquantitative RT -PCR measurement of gene expression in rat tissues including a correction for varying cell size and number. Nutrition and Metabolism 4:26.

Rosen ED, and Spiegelman BM. 2006. Adipocytes as regulators of energy balance and glucose homeostasis. Nature 444:847-853.

Rotondo F, Ho-Palma AC, Remesar X, Fernandez-Lopez JA, Romero MD, and Alemany M. 2017. Glycerol is synthesized and secreted by adipocytes to dispose of excess glucose, via glycerogenesis and increased acyl-glycerol turnover. Scientific Reports 7:8983. $10.1038 / \mathrm{s} 41598-017-09450-4$

Rotondo F, Romero MM, Ho-Palma AC, Remesar X, Fernandez-Lopez JA, and Alemany M. 2016. Quantitative analysis of rat adipose tissue cell recovery, and non-fat cell volume, in primary cell cultures. PeerJ 4:e2725. 10.7717/peerj.2725

Ruan H, Zarnowski MJ, Cushman SW, and Lodish HF. 2003. Standard isolation of primary adipose cells from mouse epididymal fat pads induces inflammatory mediators and downregulates adipocyte genes. Journal of Biological Chemistry 278:47585-47593. 
676 Sabater D, Arriarán S, Romero MM, Agnelli S, Remesar X, Fernández-López JA, and Alemany

677

678

679

680

681

682

683

684

685

686

687

688

689

690

691

692

693

694

695

696

697

698

699

700

701

702

703

M. 2014. Cultured 3T3L1 adipocytes dispose of excess medium glucose as lactate under abundant oxygen availability. Scientific Reports 4:e3663. 10.1038/srep03663

Schemmel R, Mickelsen O, and Tolgay Z. 1969. Dietary obesity in rats: Influence of diet, weight, age, and sex on body composition. American Journal of Physiology 216:373-379.

Scherer PE. 2006. Adipose tissue. From lipid storage compartment to endocrine organ. Diabetes $55: 1537-1545$.

Schmidt K, and Katz J. 1969. Metabolism of pyruvate and L-lactate by rat adipose tissue. Journal of Biological Chemistry 244:2125-2131.

Sjöström L. 1990. Oxygen-consumption of human adipose-tissue. American Journal of Physiology 259:E599-E599.

Smith SB, Lin KC, Wilson JJ, Lunt DK, and Cross HR. 1998. Starvation depresses acylglycerol biosynthesis in bovine subcutaneous but not intramuscular adipose tissue homogenates. Comparative Biochemistry and Physiology B 120:165-174.

Smith U. 1972. Studies of human adipose tissue in culture. I. Incorporation of glucose and release of glycerol. Anatomical Record 172:597-602.

Torio-Padron N, Huotari AM, Eisenhardt SU, Borges J, and Stark GB. 2010. Comparison of preadipocyte yield, growth and differentiation characteristics from excised versus aspirated adipose tissue. Cells Tissues Organs 191:365-371.

van der Merwe MT, Crowther NJ, Schlaphoff GP, Boyd IH, Gray IP, Joffe BI, and Lönnroth PN. 1998. Lactate and glycerol release from the subcutaneous adipose tissue of obese urban women from South Africa; Important metabolic implications. Journal of Clinical Endocrinology and Metabolism 83:4084-4091.

Vaughan M. 1962. The production and release of glycerol by adipose tissue incubated in vitro. Journal of Biological Chemistry 237:3354-3358.

Vitali A, Murano I, Zingaretti MC, Frontini A, Ricquier D, and Cinti S. 2012. The adipose organ of obesity-prone C57BL/6J mice is composed of mixed white and brown adipocytes. Journal of Lipid Research 53:619-629. 
704 White UA, and Tchoukalova YD. 2014. Sex dimorphism and depot differences in adipose tissue 705 function. Biochimica et Biophysica Acta 1842:377-392.

706 Wisse BE. 2004. The inflammatory syndrome: The role of adipose tissue cytokines in metabolic 707

708

709

710

711

712

713

714

715

716 disorders linked to obesity. Journal of the American Society of Nephrology 15:2792-2800.

Wood FC, Leboeuf B, and Cahill GF. 1960. Metabolic role of glucose. A source of glycerideglycerol in controlling the release of fatty acids by adipose tissue. Diabetes 9:261-263.

Wu J, Boström P, Sparks LM, Ye L, Choi JH, Giang AH, Khandekar M, Virtanen KA, Nuutila P, Schaart G, Huang KX, Tu H, van Marken Lichtenbelt WD, Hoeks J, Enerbäck S, Schrauwen P, and Spiegelman BM. 2012. Beige adipocytes are a distinct type of thermogenic fat cell in mouse and human. Cell 150:366-376.

Zuk PA, Zhu M, Ashjian P, de Ugarte DA, Huang JI, Mizuno H, Alfonso ZC, Fraser JK, Benhaim P, and Hedrick MH. 2002. Human adipose tissue is a source of multipotent stem cells. Molecular Biology of the Cell 13:4279-4295. 


\section{Figure 1}

WAT sites and adipocyte size

Panel $[A]$ depicts microphotographs of representative isolated adipocyte preparations from subcutaneous, mesenteric and epididymal WAT. The cells were viewed in a Neubauer chamber. Main grid squares were $250 \mu \mathrm{m}$ wide (and had a volume of $6.25 \mathrm{~nL}$ each). Panel [B] shows the mean adipocyte volume in WAT sites extracted from undisturbed female and male adult Wistar rats. The data are the mean \pm sem of 4 groups of 2 rat-pools for sex and site. SC = subcutaneous WAT; MES = mesenteric WAT; PG perigonadal (epididymal - males, periovaric - females) WAT; blue bars, $\mathrm{M}=$ male rats; mauve (clear) bars, $\mathrm{F}=$ female rats.

Statistical comparison between groups: two-way ANOVA; the p values for sex (green) and site (red) are included in the Figure. NS = not significant $(p>0.05)$. 


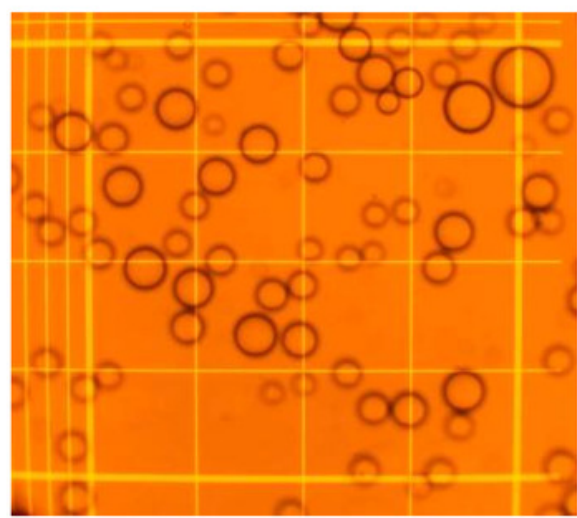

A SUBCUTANEOUS

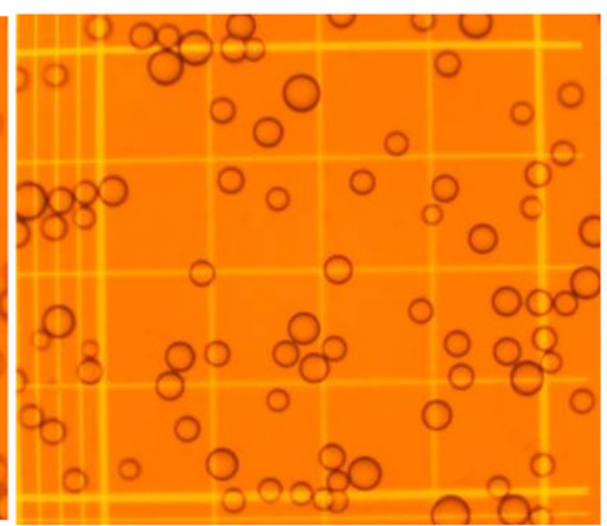

MESENTERIC

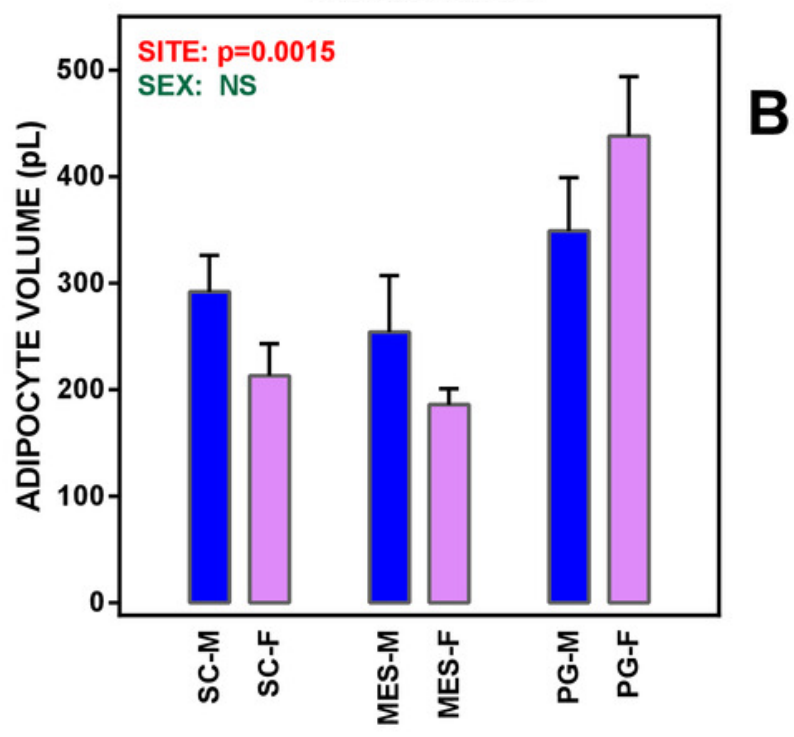

B

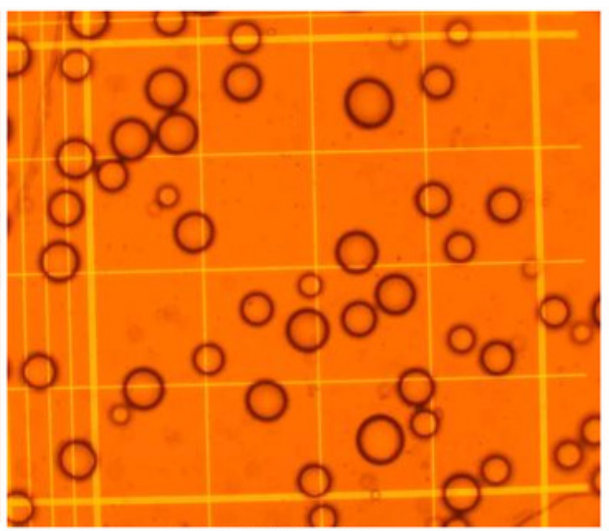

EPIDIDYMAL 


\section{Figure 2}

Glucose uptake rates and lactate, glycerol and NEFA efflux rates (all in attomoles per second and cell) of adipocytes obtained from three WAT sites of male and female adult Wistar rats

The data are the mean \pm sem of 4 groups of 2 rat-pools for sex and site, incubated for 24 or $48 \mathrm{~h}$. The abbreviations for site and sex are the same as in Figure 1. [A] Glucose uptake, [B lactate effl, [C] glycerol efflux, [D] NEFA efflux. The statistical significance of the differences between groups was investigated using 2-, 3- and 4-way ANOVA analyses and the variables: WAT Site, Sex (S), medium Glucose concentration (G) and Time of incubation (T). The Figure shows the 3- $(S, G, T)$ and 2- way ANOVA $(G, T)$ analyses for each site; the data are included in blue boxes (3-way) encompassing each site and showing the corresponding $p$ values when statistically significant $(p<0.05)$, or gray boxes ( 2 -way) with significant $p$ values for each sex within a given WAT site. The 4-way ANOVA values were, Site: $p<0.001$ for all parameters except $p=0.0081$ (lactate): Sex: $p<0.0001$ for glycerol and NEFA, and $p=0.0046$ for glucose; Glucose concentration: $p<0.0001$ for glucose; Time of incubation: $p<0.0001$ for NEFA, $p=0.0001$ for glycerol and $p=0.0133$ for lactate. 

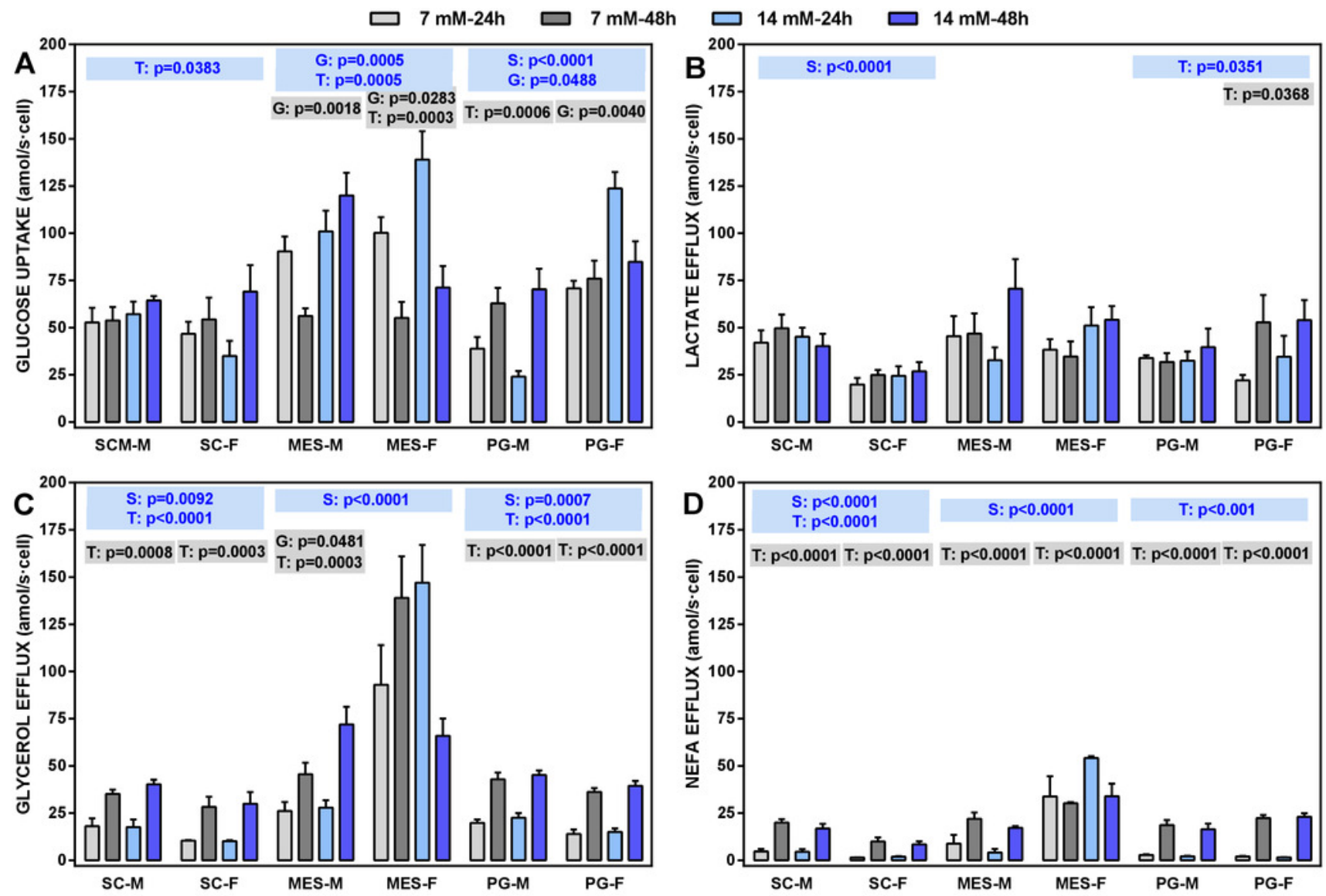


\section{Figure 3}

Expression of genes related with the metabolism of glucose, lipogenesis and $3 \mathrm{C}$ handling in adipocytes of male and female adult rats incubated in the presence of $7 \mathrm{mM}$ or $14 \mathrm{mM}$ glucose (I)

The data are the mean \pm sem of 4 (or 3) groups of 2 rat-pools for sex and site, incubated for 24 or $48 \mathrm{~h}$, and represent the number of mRNA copies per cell of each gene. The data are presented on a log scale. Blue circles indicate males: deep blue $14 \mathrm{mM}$ glucose, light blue 7 $\mathrm{mM}$ glucose; purple circles represent females: violet-purple $14 \mathrm{mM}$ glucose, mauve $7 \mathrm{mM}$ glucose. $\mathrm{SC}=$ subcutaneous, $\mathrm{MES}=$ mesenteric and PG = perigonadal WAT. [A] Glut1, [B] Hk1, [C] Pfkl. [D] Phgdh, [E] G6pdx, [F] Me1. Statistical analysis of the differences between groups: The figures contain the p values for a 3-way ANOVA analysis (sex [S in green], glucose [G in blue] and time of incubation [T in purple]) applied to each site. Results of twoway ANOVA for these paramers are also represented: the letters and colors are the same, adding $m$ for male and $f$ for female subgroups; for 2-way ANOVAs, the $p$ values are represented by up to three stars, corresponding to three levels of statistical significance of the differences $(p<0.05, p<0.01$ and $p<0.001)$. Only significant differences have been represented. The results for 4 -way ANOVAs were significant $(p<0.0001)$ for time in all gene expressions. The effect of sex was significant only for Pfkl $(p=0.0006)$ and Mel $(p=0.0007)$, that of glucose concentration was significant for HKI $(p=0.0371)$, Phgdh $(p=0.0164)$ and Me1 $(p=0.206)$. The effect of time of incubation was significant for Glutl $(p=0.0023)$ and Pfkl, Phgdh, and G6pdx ( $p<0.0001)$. Non-statistically significant data $(p>0.05)$ were not represented. 


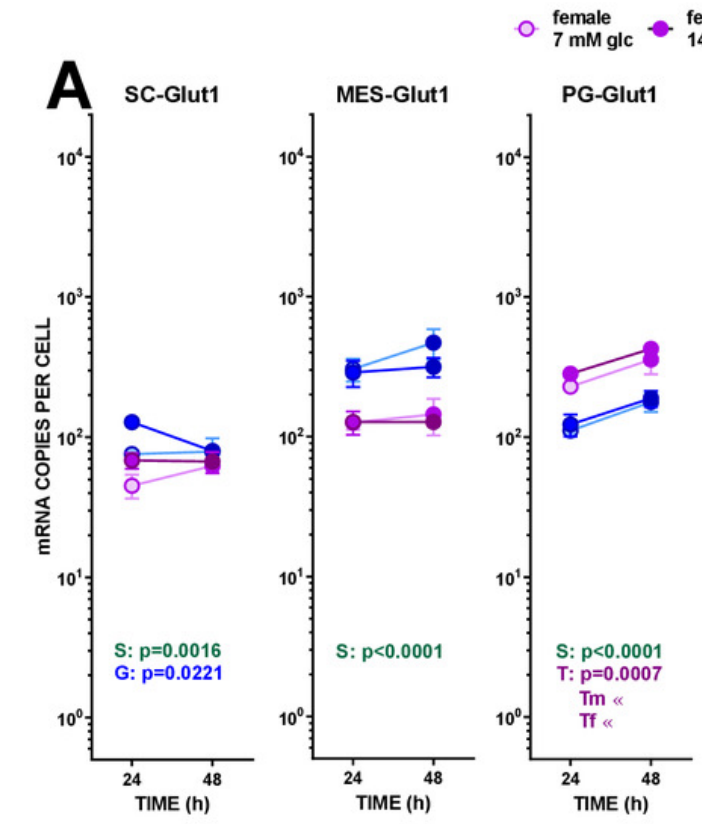

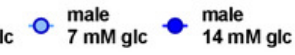
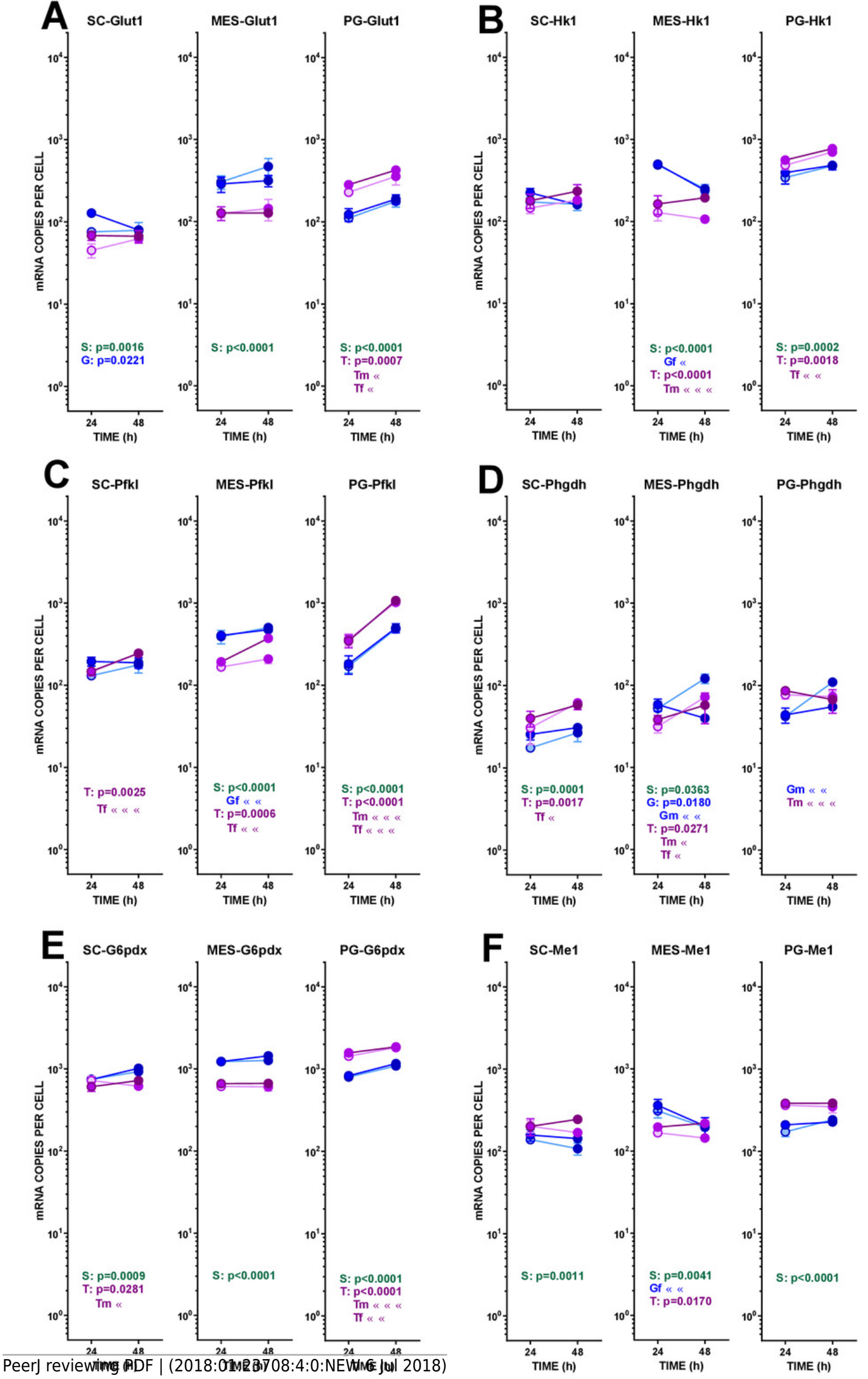


\section{Figure 4}

Expression of genes related with the metabolism of glucose, lipogenesis and $3 \mathrm{C}$ handling in adipocytes of male and female adult rats incubated in the presence of $7 \mathrm{mM}$ or $14 \mathrm{mM}$ glucose (II)

The data are the mean \pm sem of 4 (or 3 ) groups of 2 rat-pools for sex and site, incubated for 24 or $48 \mathrm{~h}$, and represent the number of mRNA copies per cell of each gene. The distribution figure set-up and other conventions are those described in Figure 4. [1] Ldha, [B] Ldhb, [C] Pdk4, [D] Pck1, [E] Mct1, [F] Cpt1b. The results for 4-way ANOVAs were significant $(p<0.0001)$ for time in all gene expressions. The effect of sex was significant only for $L d h b$ $(p=0.0063)$, that of glucose concentration was significant only for $L d h a(p=0.0037)$. The effect of time of incubation was significant $(p<0.0001)$ for all genes except $L d h b$ (NS). 


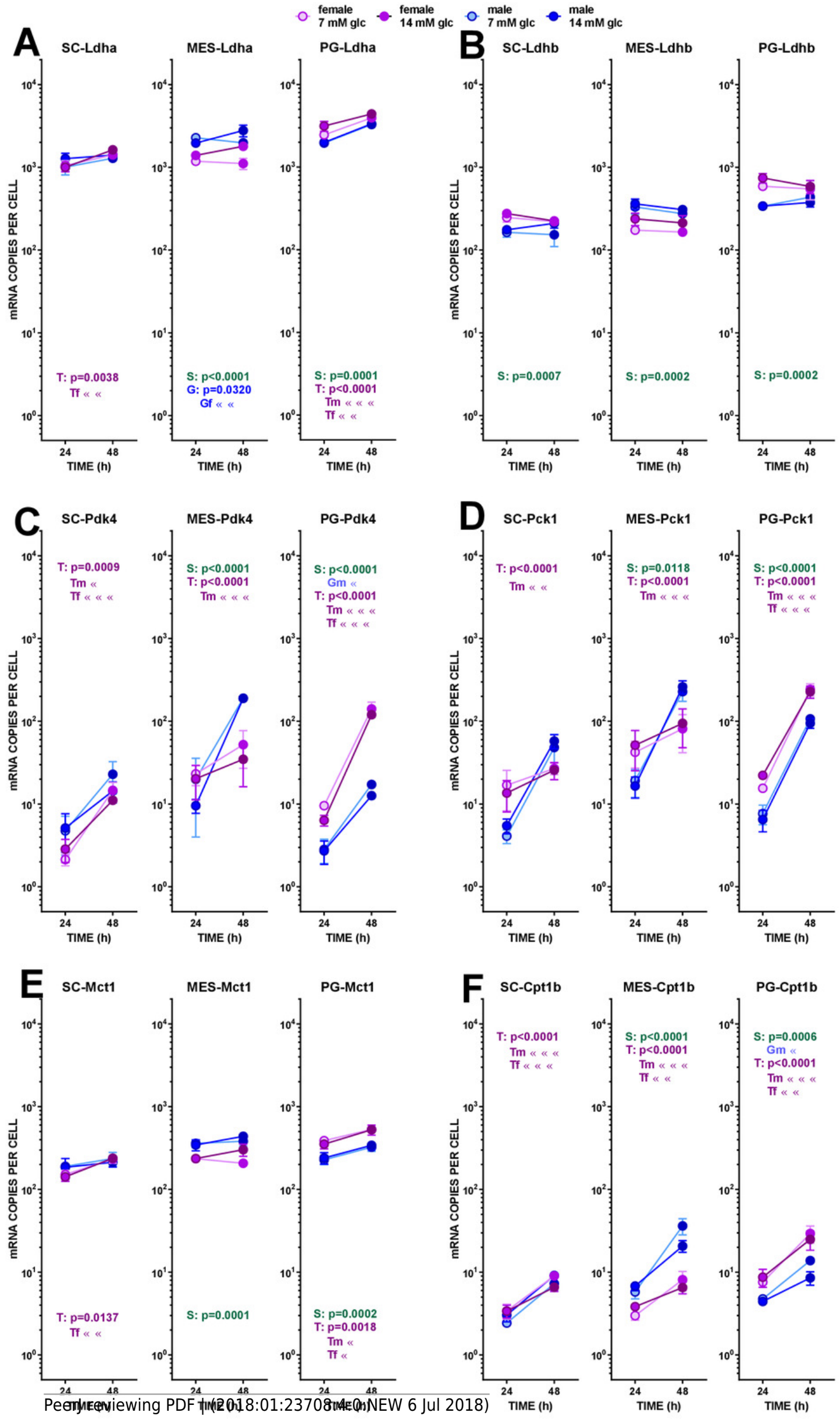




\section{Figure 5}

Expression of genes related with the metabolism of glucose, lipogenesis and $3 \mathrm{C}$ handling in adipocytes of male and female adult rats incubated in the presence of $7 \mathrm{mM}$ or $14 \mathrm{mM}$ glucose (III)

The data are the mean \pm sem of 4 (or 3 ) groups of 2 rat-pools for sex and site, incubated for 24 or $48 \mathrm{~h}$, and represent the number of mRNA copies per cell of each gene. The distribution figure set-up and other conventions are those described in Figure 4. [1] Gdp1, [B] Gpam, [C] Pgp, [D] Gk, [E] Aqp7, [F] Cd36. The results for 4-way ANOVAs were significant $(\mathrm{p}<0.0001)$ for time in all gene expressions ( $p=0.0030$ for $C d 36$ and $p<0.0001$ for all others). The effect of sex was significant only for Pgp $(p<0.0001)$ and $G K(p=0.0001)$ Glucose concentration did not elicit any significant change of expression. The effect of time of incubation was significant ( $p<0.0001)$ for Gpd1, Gpam, Gk and Cd36. 


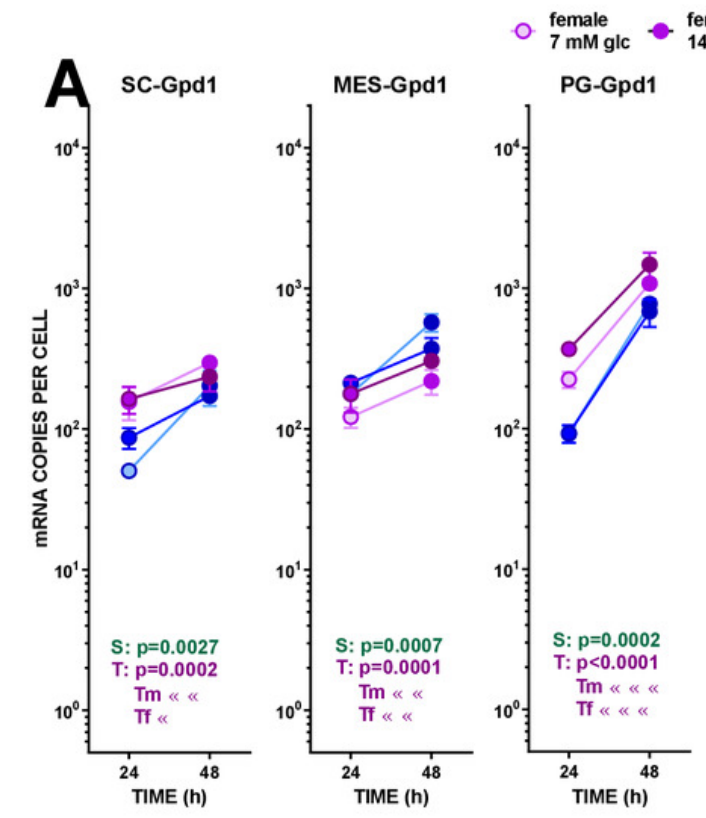

$\begin{aligned} & \text { male } \\ & 7 \mathrm{mM} \text { glc }\end{aligned}-\begin{aligned} & \text { male } \\ & 14 \mathrm{mM} \text { glc }\end{aligned}$
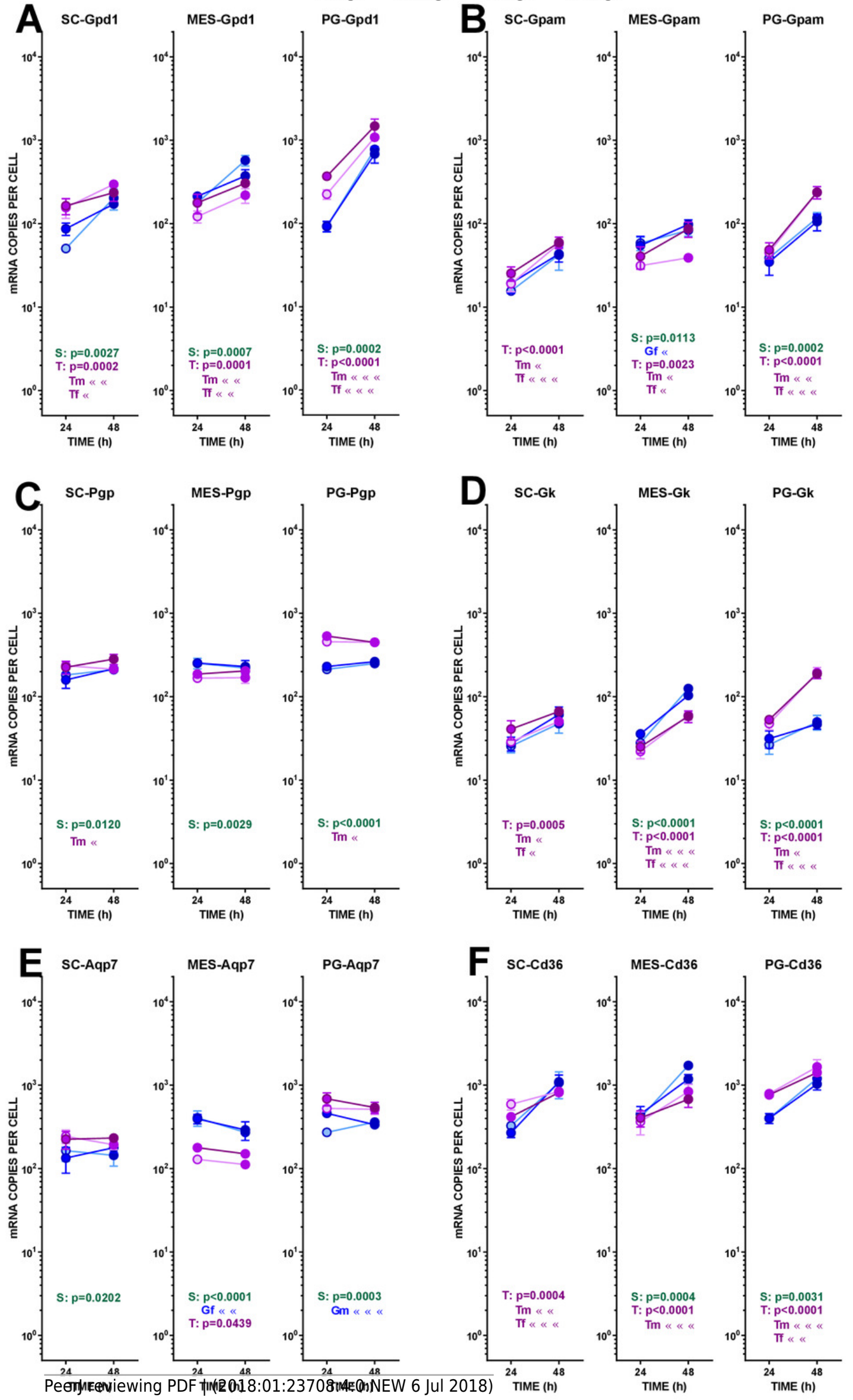


\section{Figure 6}

Expression of genes related with the metabolism of glucose, lipogenesis and $3 \mathrm{C}$ handling in adipocytes of male and female adult rats incubated in the presence of $7 \mathrm{mM}$ or $14 \mathrm{mM}$ glucose (IV)

The data are the mean \pm sem of 4 (or 3 ) groups of 2 rat-pools for sex and site, incubated for 24 or $48 \mathrm{~h}$, and represent the number of mRNA copies per cell of each gene. The distribution figure set-up and other conventions are those described in Figure 4. [1] Acaca, [B] Fas, [C] Acly, [D] Lpl, [E] Hsl, [F] Atgl. The results for 4-way ANOVAs were significant $(p<0.0001)$ for time in all gene expressions. The effect of sex was significant for Fas and $A c l y(p<0.0001)$, $L p l(p=0.0001$, Acaca $(p=0.0020)$ and $\mathrm{Hsl}(p=0043)$; that of glucose concentration was significant only for Fas $(p=0.0003)$ and $A c l y(p=0.0118)$. The effect of time of incubation was significant for $L p l, H s l, A t g l(p<0.0001)$, and Fas $(p=0-014)$. 


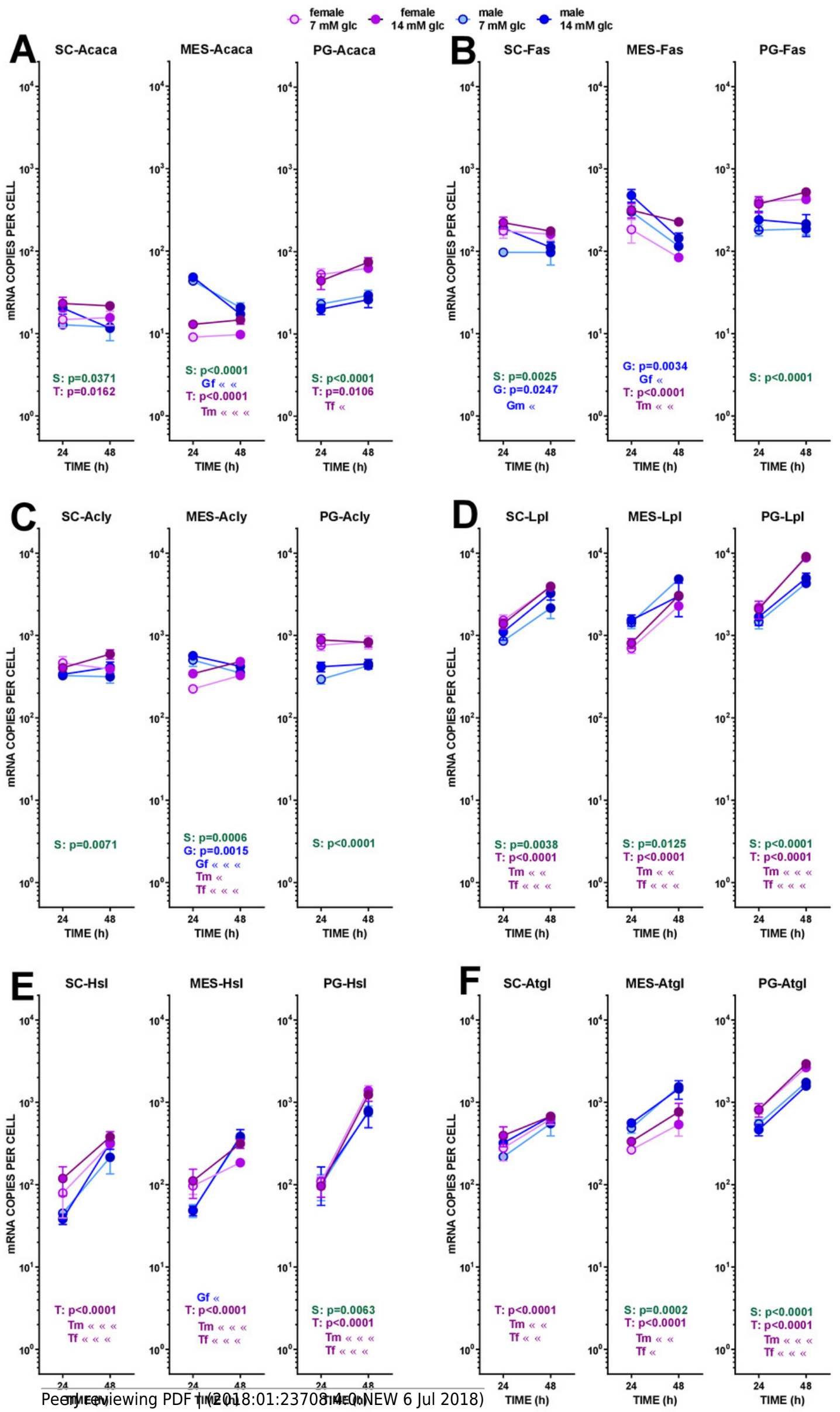


Figure 7

Diagram showing the position of the genes investigated on a scheme of the main adipocyte energy metabolism pathways

Blue: genes (for enzymes and transporters); white: metabolites.

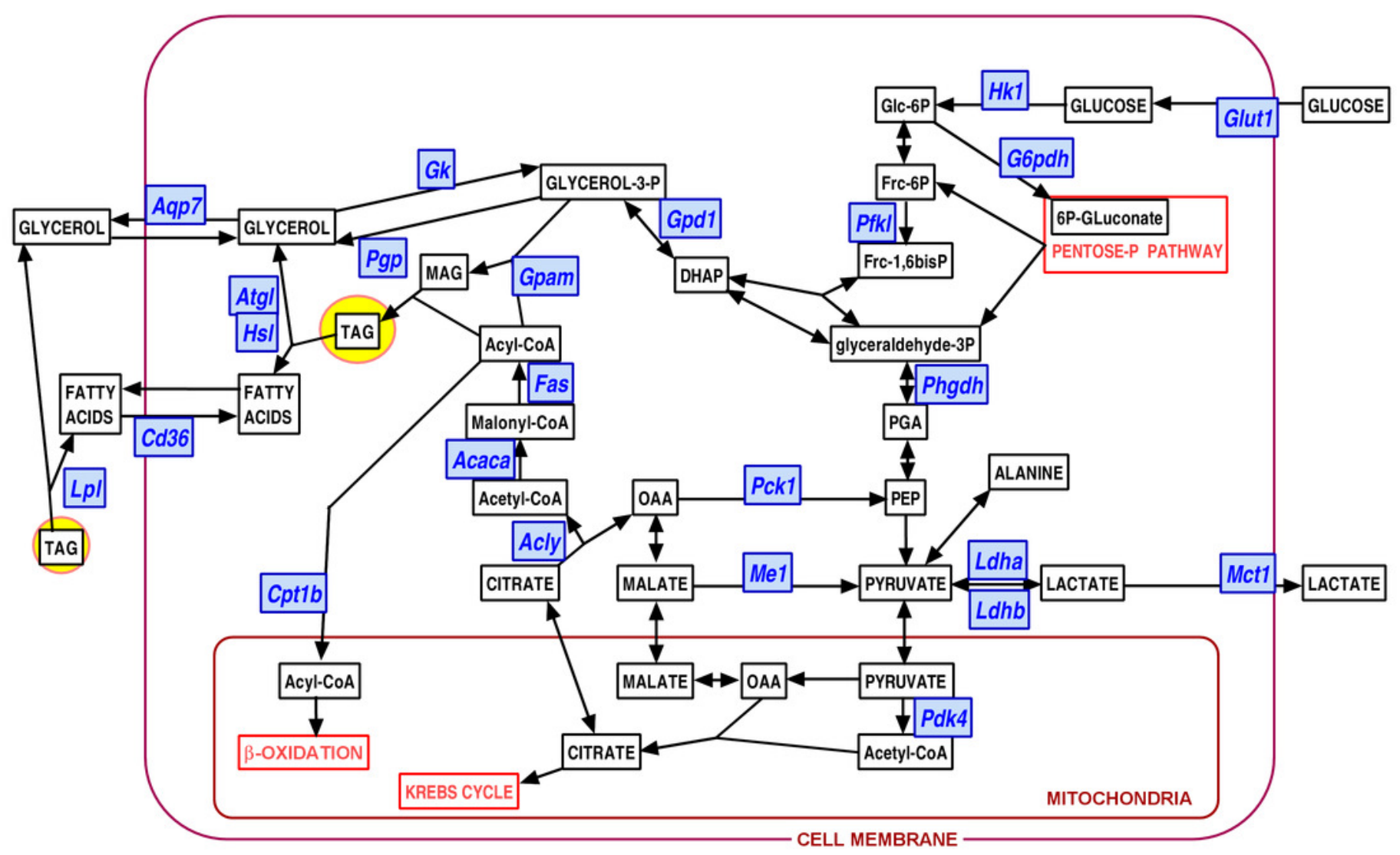




\section{Table 1 (on next page)}

List of primers used in the present study 
1 TABLE 1 List of primers used in the present study

\begin{tabular}{|c|c|c|c|c|}
\hline gene & protein & direction & sequences & $\mathrm{bp}$ \\
\hline \multirow{2}{*}{$\begin{array}{l}\text { (Glut-1) } \\
\text { Slc2al }\end{array}$} & \multirow{2}{*}{$\begin{array}{l}\text { Glucose transporter type } 1 \text {, } \\
\text { erythrocyte/brain }\end{array}$} & $5^{\prime}>$ & GCTCGGGTATCGTCAACACG & \multirow{2}{*}{97} \\
\hline & & $>3^{\prime}$ & ATGCCAGCCAGACCAATGAG & \\
\hline \multirow{2}{*}{$H k 1$} & \multirow{2}{*}{ Hexokinase type 1} & $5^{\prime}>$ & TGGATGGGACGCTCTACAAA & \multirow{2}{*}{100} \\
\hline & & $>3^{\prime}$ & GACAGGAGGAAGGACACGGTA & \\
\hline \multirow{2}{*}{ Pfkl } & \multirow{2}{*}{$\begin{array}{l}\text { Phospho-fructokinase, liver, b- } \\
\text { type }\end{array}$} & $5^{\prime}>$ & CAGCCACCATCAGCAACAAT & \multirow{2}{*}{90} \\
\hline & & $>3^{\prime}$ & TGCGGTCACAACTCTCCATT & \\
\hline \multirow{2}{*}{ Phgdh } & \multirow{2}{*}{$\begin{array}{l}\text { Phospho-glycerate } \\
\text { dehydrogenase }\end{array}$} & $5^{\prime}>$ & CTGAACGGGAAGACACTGGGAA & \multirow{2}{*}{138} \\
\hline & & $>3^{\prime}$ & AACACCAAAGGAGGCAGCGA & \\
\hline \multirow{2}{*}{ G6pdx } & \multirow{2}{*}{$\begin{array}{l}\text { Glucose-6-phosphate } \\
\text { dehydrogenase X-linked }\end{array}$} & $5^{\prime}>$ & GACTGTGGGCAAGCTCCTCAA & \multirow{2}{*}{77} \\
\hline & & $>3^{\prime}$ & GCTAGTGTGGCTATGGGCAGGT & \\
\hline \multirow{2}{*}{ Mel } & \multirow{2}{*}{$\begin{array}{l}\mathrm{NADP}^{+} \text {-dependent malic } \\
\text { enzyme }\end{array}$} & $5^{\prime}>$ & GGAGTTGCTCTTGGGGTAGTGG & \multirow{2}{*}{143} \\
\hline & & $>3^{\prime}$ & CGGATGGTGTTCAAAGGAGGA & \\
\hline \multirow{2}{*}{ Ldha } & \multirow{2}{*}{ L-lactate dehydrogenase a } & $5^{\prime}>$ & AAAGGCTGGGAGTTCATCCA & \multirow{2}{*}{96} \\
\hline & & $>3^{\prime}$ & CGGCGACATTCACACCACT & \\
\hline \multirow{2}{*}{$L d h b$} & \multirow{2}{*}{ L-lactate dehydrogenase $b$} & $5^{\prime}>$ & GCGAGAACTGGAAGGAGGTG & \multirow{2}{*}{145} \\
\hline & & $>3^{\prime}$ & GGGTGAATCCGAGAGAGGTTT & \\
\hline \multirow{2}{*}{$P d k 4$} & Pyruvate dehydrogenase & $5^{\prime}>$ & CTGCTCCAACGCCTGTGAT & 142 \\
\hline & kinase, isoenzyme 4 & $>3^{\prime}$ & GCATCTGTCCCATAGCCTGA & \\
\hline Pckl & Phosphoenol-pyruvate & $5^{\prime}>$ & CGGGTGGAAAGTTGAATGTG & 142 \\
\hline & carboxykinase, cytosolic & $>3^{\prime}$ & AATGGCGTTCGGATTTGTCT & \\
\hline Mctl & Monocarhoxylate transnorter & $5^{\prime}>$ & CCCAGAGGTTCTCCAGTGCT & 133 \\
\hline & Nionocalouxyrate trantsporter & $>3^{\prime}$ & ACGCCACAAGCCCAGTATGT & \\
\hline Cptlb & Carnitine O-palmitoleoyl- & $5^{\prime}>$ & TGCTTGACGGATGTGGTTCC & 152 \\
\hline & transferase 1 , muscle isoform & $>3^{\prime}$ & GTGCTGGAGGTGGCTTTGGT & \\
\hline Godl & Glycerol 3-phosphate & $5^{\prime}>$ & CTGGAGAAAGAGATGCTGAACG & 113 \\
\hline Uai & dehydrogenase & $>3^{\prime}$ & GCGGTGAACAAGGGAAACTT & \\
\hline Gnam & Glycerol-3-phosphate acyl- & $5^{\prime}>$ & GGTGAGGAGCAGCGTGATT & 12 \\
\hline Gpam & transferase, mitochondrial & $>3^{\prime}$ & GTGGACAAAGATGGCAGCAG & \\
\hline Pgp & Phosphoglycolate phosphatase & $5^{\prime}>$ & CCTGGACACAGACATCCTCCT & \\
\hline & & $>3^{\prime}$ & TTCCTGATTGCTCTTCACATCC & 100 \\
\hline$G k$ & Glvcerol kinase & $5^{\prime}>$ & ACTTGGCAGAGACAAACCTGTG & 74 \\
\hline & & $>3^{\prime}$ & ACCAGCGGATTACAGCACCA & \\
\hline Aap 7 & Aquaporin 7 & $5^{\prime}>$ & ACAGGTCCCAAATCCACTGC & 127 \\
\hline$A q p /$ & Aquapom & $>3^{\prime}$ & CCGTGATGGCGAAGATACAC & 121 \\
\hline$C D 36$ & Platelet glycoprotein 4 [fatty & $5^{\prime}>$ & TGGTCCCAGTCTCATTTAGCC & 154 \\
\hline & acid transporter] & $>3^{\prime}$ & TTGGATGTGGAACCCATAACTG & \\
\hline Acaca & Acetyl-CoA carboxvlase 1 & $5^{\prime}>$ & AGGAAGATGGTGTCCGCTCTG & 145 \\
\hline & & $>3^{\prime}$ & GGGGAGATGTGCTGGGTCAT & \\
\hline$F a_{\mathrm{s}}$ & Fatty acid synthase & $5^{\prime}>$ & CCCGTTGGAGGTGTCTTCA & 117 \\
\hline & & $>3^{\prime}$ & AAGGTTCAGGGTGCCATTGT & \\
\hline Aclv & ATP citrate lvase & $5^{\prime}>$ & TGTGCTGGGAAGGAGTATGG & 137 \\
\hline Acly & A ir cruate ryase & $>3^{\prime}$ & GCTGCTGGCTCGGTTACAT & 151 \\
\hline
\end{tabular}




\begin{tabular}{|c|c|c|c|c|}
\hline \multirow{2}{*}{$L p l$} & \multirow{2}{*}{ Lipoprotein lipase } & $5^{\prime}>$ & TGGCGTGGCAGGAAGTCT & \multirow{2}{*}{116} \\
\hline & & $>3^{\prime}$ & CCGCATCATCAGGAGAAAGG & \\
\hline \multirow{2}{*}{$\begin{array}{l}\text { (Hsl) } \\
\text { Lipe }\end{array}$} & \multirow{2}{*}{ Lipase, hormone sensitive } & $5^{\prime}>$ & TCCTCTGCTTCTCCСТCTCG & \multirow{2}{*}{108} \\
\hline & & $>3^{\prime}$ & ATGGTCCTCCGTCTCTGTCC & \\
\hline \multirow{2}{*}{$\begin{array}{l}\text { (Atgl) } \\
\text { Pnpla2 }\end{array}$} & \multirow{2}{*}{ Adipose triacylglycerol lipase } & $5^{\prime}>$ & CACCAACACCAGCATCCAAT & \multirow{2}{*}{120} \\
\hline & & $>3^{\prime}$ & CGAAGTCCATCTCGGTAGCC & \\
\hline \multirow{2}{*}{ Arbp } & \multirow{2}{*}{$\begin{array}{l}\text { 0S acidic ribosomal phospho- } \\
\text { protein PO [housekeeping gene] }\end{array}$} & $5^{\prime}>$ & CCTTCTCCTTCGGGCTGAT & \multirow{2}{*}{122} \\
\hline & & $>3^{\prime}$ & CACATTGCGGACACCCTCTA & \\
\hline
\end{tabular}

2 